\title{
Can water systems foster commoning practices? Analysing leverages for self- organization in urban water commons as social-ecological systems
}

Article

Accepted Version

Perrotti, D., Hyde, K. and Peña, D. O. (2020) Can water systems foster commoning practices? Analysing leverages for self-organization in urban water commons as social-ecological systems. Sustainability Science, 15 (3). pp. 781-795. ISSN 1862-4065 doi: https://doi.org/10.1007/s11625-020-00782-1 Available at https://centaur.reading.ac.uk/85804/

It is advisable to refer to the publisher's version if you intend to cite from the work. See Guidance on citing.

To link to this article DOI: http://dx.doi.org/10.1007/s11625-020-00782-1

Publisher: Springer

All outputs in CentAUR are protected by Intellectual Property Rights law, including copyright law. Copyright and IPR is retained by the creators or other copyright holders. Terms and conditions for use of this material are defined in the End User Agreement. 


\section{CentAUR}

Central Archive at the University of Reading

Reading's research outputs online 


\title{
Can water systems foster commoning practices? Analysing leverages for self- organization in urban water commons as social-ecological systems.
}

\author{
Abstract \\ Research into urban commons has gained momentum in recent years. This article \\ concentrates on the concept and analysis of urban water commons as social-ecological \\ systems, which receive a less prominent focus in the literature than other commoning \\ practices. In the light of the distinctive social and ecological values of water for both \\ ecosystem health and human wellbeing and sociability, we argue that the presence of \\ water systems can foster stakeholder engagement and leverage self-organization in \\ urban commons. We test our hypothesis in a dynamically-evolving urban water \\ common: the recently restored Geoffrey Jellicoe's Water Gardens in Hemel Hempstead, \\ England. We apply Elinor Ostrom's multilevel diagnostic tool, the "Social-Ecological \\ System framework", to analyse the characteristics of the Gardens water system and their \\ impact on the self-organizing process undertaken by the local community. Our \\ application is supported by collection of primary and secondary data, including \\ Jellicoe's design archived evidence, field observation data, in-depth interviews with key \\ stakeholders, as well as data mining from social media (topic modelling of Facebook \\ posts, review of Facebook user profiles, and Twitter mention-network analysis). \\ Through our results, we identify a broad spectrum of characteristics of the Gardens \\ urban water common that can catalyse the local self-organization dynamics. These \\ include the leadership position of a specific non-governmental actor group with \\ knowledge and expertise on water ecosystems; active engagement of the local \\ population across age groups in recreational activities on the water; community-
}


building through expertise and knowledge sharing on the peculiar natural and infrastructural components of the Gardens water systems; and, finally, continued online networking and social media communication among different stakeholder groups on water-related activities.

\section{Keywords}

Green and Blue Infrastructure, Social-Ecological System Framework, Governance Systems, Water Systems Management, Big Data, Social Media.

\section{Introduction}

\subsection{Urban commons as social-ecological systems}

The concept of "urban common" has in recent years gained significant success in interdisciplinary studies discussing a broad variety of social and ecological dynamics occurring in urban spaces. Within the scope of this article, we define "urban commons" as public spaces contained within urban regions in which communities of individuals self-organize in order to manage a resource collectively (e.g. water, crops, or simply land). Complementarily, the expression "commoning actions" or "commoning practices" refer to the social and institutional practices that are required to manage a common-pool resource and are grounded on bottom-up governance systems (Petrescu et al. 2017). Commoning actions and practices are frequently undertaken on a voluntaristic basis through interactions amongst individuals who share an identity, leading to dynamic forms of self-management alternatively or in conjunction with governmental management regimes. 


\footnotetext{
${ }^{1}$ Equitable access is a traditional and essential element of commoning practices in the UK since the 16th century. This involved access for all local people to common grazing, tethering and livestock sustenance on a designated land. More recently, the Commons Act 2006 introduced reforms to the property rights regime for common land, which provided a more equitable basis for land-resource access (Rodgers et al., 2011).
}

The popularity of the concept in both social and environmental sciences has been leveraged by a growing interest in Elinor Ostrom's $(1990,2008)$ work and intellectual legacy promoting an understanding of urban commons as social-ecological systems (SESs) (e.g. Radywyl and Biggs 2013; Colding et al. 2013; Colding and Barthel 2013; Egerer and Fairbairn 2018). A Scopus search conducted in January 2019 showed that, following Ostrom's pivotal work in 1990, 182 articles and book chapters containing "urban commons" in the title, abstract or keywords were published in English between 1995 and 2018 (of which, 142 published from 2013 to 2018).

Several urban common studies in western countries and the Global South (e.g. Murphy et al. 2019; Petrescu et al. 2017; Follman and Viehoff 2015; Mundoli et al. 2015; Radywyl and Biggs 2013) show a clear convergence between commoning practices and overall sustainability concerns, or between commoning and resilient strategies. In these studies, sustainability and resilience provide a broader umbrella topic embracing the focus on equitable access and use of land which has traditionally been at the heart of commons' research ${ }^{1}$ (Ostrom 1990). Some authors argue that self-organization dynamics and shared interests in common-resource management among actors can support the development of new behavioural, cultural and structural configurations which are primary drivers of sustainable urban transformation over time (Radywyl and Biggs 2013; Marshall 2008). Hence urban commons have been studied as vectors of new bottom-up forms of sustainability and testing grounds for "co-produced resilience 
processes" (Petrescu et al. 2017). These multiple entanglements make urban commons a compelling subject and fertile ground for sustainability science.

\subsection{Knowledge gap and research question: urban water commons}

Water systems have provided a strong focus in Ostrom's work on commons and related self-organizing processes (Ostrom 1990). However, urban water commons have received less attention in contemporary literature than other urban commoning practices. When the abovementioned Scopus search $(1995$ - 2018) is streamlined using the "urban commons AND water" criterion, outputs are reduced down to six. This knowledge gap is particularly compelling once we take into consideration the distinctive values of water systems for both human health and the functionality of urban ecosystems (Perrotti and Iuorio 2018). As demonstrated by a growing portfolio of research, these values are of both social and ecological nature and result from the specific characteristics of water, its essential life functions for humans and ecosystems, and the relationship that communities establish with it. For example, the presence of water can contribute to enhancing human interactions in urban public spaces as well as foster actual and perceived health and wellbeing of individuals (Cracknell et al. 2018; Murphy et al. 2019). Aquatic organisms can assist in maintaining water quality and aquatic species diversity can increase functional robustness and biodiversity of other species, sustaining the robustness of the overall ecosystem (Elmqvist et al. 2003). In light of these distinctive social-ecological values of water and their positive influence on healthier and more resilient SESs, the research presented in this article explores whether and how the presence of water systems in urban public spaces can foster community engagement and leverage self-organization in urban commons. Our 
underlying hypothesis is that the common use and collective management of water systems in urban environments can promote the internal cohesion of communities sharing a resource and, consequently, can leverage urban commoning practices. For the purpose of addressing our research question, we use the Hemel Hempstead Water Gardens in the Borough of Dacorum, Hertfordshire, England, as a case study. We apply the multilevel SES framework proposed by Elinor Ostrom (2008) as a method to analyse our case and test our hypothesis, supported by a collection of primary and secondary data. The Water Gardens were designed by landscape architect Geoffrey Jellicoe (1957-1959), founding member of the International Federation of Landscape Architects and of the UK Landscape Institute. They were placed on the English Heritage's Register of Parks and Gardens of Special Historic Interest (2010), and, under the initiative of Dacorum Borough Council, recently restored by the practice HTA Design LLP, London (2014-2017). The Gardens social-ecological values are enhanced both by design attributes and elements of local governance. Moreover, the clear identification with water as manifested in their name makes the Gardens a particularly relevant case for evaluating how water systems can foster urban commoning practices.

The article is structured as follows. In Background, fundamental principles of the Ostrom's SES framework are introduced. In Case Study, we present the main characteristics of the Water Gardens urban common which guided the application of the SES framework. Then, we describe the method we employed to adapt and apply the framework to our case study as well as the primary and secondary data collected to inform our application. Subsequently, we present the outcomes of our case study and data collection. Finally, we discuss key characteristics of the Gardens' water system 
which, following the framework application, were identified as catalyst for the local commoming practices and self-organizing process.

\section{Background}

Ostrom's $(2007,2009)$ multilevel, nested SES framework (amended by McGinnis and Ostrom 2014) was conceived as a tool to study the relationships among the multiple levels that compose a common, while providing the basis for shared diagnosis and understanding of commons among disciplines. Its application can support the identification of the SES's main characteristics and provide insights into modes of interaction and self-organizing processes among actors involved in the collective management of the common-pool resource.

In the framework, firstly SESs are analysed based on the description of four main subsystems composing the system, as well as by any direct and indirect influence each subsystem has on the others (Figure 1). The subsystems are: (i) Resource Systems (e.g. a water system); (ii) Resource Units (natural and infrastructural components of the resource system); (iii) Governance Systems (governmental and non-governmental policy and measures for the management of the resource system); and (iv) Actors ${ }^{2}$ (individuals or organizations using the resource system for different purposes and any other involved third parties). Secondly, the peculiar character of each SES is defined through the identification of an "Action Situation" (Figure 1). The concept of "Action Situation" refers to the generation of a set of specific outcomes in a SES through

\footnotetext{
${ }^{2}$ In the original version of the SES framework proposed by Ostrom $(2007,2009)$ the "Actors" first-tier category was named "Users". It has been afterwards generalised to "Actors" by McGinnis and Ostrom (2014), on the basis that the framework should also include the behaviours of third parties not directly using the resource systems and units. This amendment is recommended for any future use.
} 
multiple forms of interactions among the actors (e.g. "commoning actions"). Hence the Action Situation of a SES is defined by the interlinks between the identified Interactions and Outcomes (named "Interactions-Outcomes (I-O) nexus") (McGinnis and Ostrom 2014). The four abovementioned subsystems and the Interactions and Outcomes defining the Action Situations represent the first-tier variables of the SES framework. They are analysed based on their mutual influences and all exogenous influences they receive from other ecosystems (ECO) or external social, economic and political settings (S).

\section{[Figure 1]}

Fig 1 First-tier variables (the four Subsystems and the Interactions-Outcomes nexus) composing the Social-Ecological System framework, and direct and feedback links among them (solid/dotted arrows). Adapted from: McGinnis and Ostrom 2014, p.4.

Each first-tier variable is decomposed into a range of second-tier variables, which can be used to describe the Interactions, Outcomes and Subsystems, and are, in turn, decomposed into third-tier variables. Second- and third-tier variables that are relevant to the studied SES can be identified and organized based on fieldwork and data collection. Recent research has demonstrated that the framework can support the implementation of transdisciplinary agendas in sustainability science and facilitate the communication of scientific knowledge to decision-makers and practitioners (Partelow 2016). Its use in case study research can also contribute to expanding the applicability of sustainability agendas to a wider range of concepts and systems (Frey 2017). When applied in urban contexts, the framework can help unfold the urban sustainability aspects that are 
embedded within commoning practices and promote an understanding of urban commons as potential vectors of socially and environmentally sustainable practices. For example, applications of the SES framework in urban contexts include analysis of changes from community-based governance to state management regimes of urban lakes commons (Nagendra and Ostrom 2014), as well as analysis of development process and governance systems of Integrated Community Energy Systems (Acosta et al. 2018). As these works demonstrate, the use of the framework can allow identifying SES characteristics and stakeholder dynamics fostering social-ecological resilience as well as help evaluate the challenges stakeholders face in achieving sustainability objectives.

\section{Case study}

\subsection{Resource System and Resource Units}

The Water Gardens are situated in the centre of Hemel Hempstead (population of 94,932 - 2011 census), located $39 \mathrm{~km}$ northwest of London, under the jurisdiction of Dacorum Borough Council (DBC). Hemel Hempstead was developed in 1947 under the British Government "New Towns Programme". Areas of land were designated for the construction of a "new town" in order to respond to the severe housing shortage in London after World War II. The Gardens have a size of approximately 3.5 hectares, extending on both sides of a north-branch channelized section of the River Gade. They have a north-south length of 615 metres and a maximum east-west width of approximately 50 metres. They are bounded to the east by a commercial street with various public facilities, and to the west by a suburban link road and a two-storey car park (Figure 2a-b). The Gardens are open to the surrounding urban space, allowing for 
full accessibility during day and night from pedestrian entrances and bridges connecting them to the town centre.

\section{[Figures 2a-2b]}

Fig 2 Aerial views of: a) the Hemel Hempstead Water Gardens, showing the surrounding commercial Waterhouse Street (east side), the suburban-link road Leighton Buzzard Road (west), Combe Street (north), and Mill End Road (south); b) location of the Water Gardens in the Hemel Hempstead town centre. The dotted lines represent the Gardens' edges and the administrative boundary of the Hemel Hempstead town.

The Gardens initially represented a key component of Jellicoe's (unbuilt) Masterplan for the Hemel Hempstead "new town", in which they served as the core recreational space at the heart of the town centre (Jellicoe, 1947). The main goal of the scheme was to provide leisure as well as social, economic, welfare and environmental benefits to the community, aligning with the aspirations of the new town programme (Jellicoe et al. 1960). A water-engineering project of moderate complexity was undertaken to create the Gardens alongside the Gade channel, including diverting a relatively fast flowing, small chalk stream into the new town centre. The stream water combines with the water from the Gade and collects into artificial, landscaped shallow lakes. The channel is crossed by four bridges, three south-flowing weirs and raised viewing platforms, and an artificial islet is located on the east side (Figure 3a). The Gardens follow a linear layout and have been designed as a collection of individual gardens defined by distinct functions. Grasses, water lilies, and other water plant species punctuate the water's edge 
for most of the Gardens' length. An area of ornamental planting ("Flower Garden") with flowers and a shrubbery crossed by a grid of regular paths was laid out on the west side of the channel (Figure 3b) (Jellicoe et al. 1960). The Gardens are recognized as an exemplary case of post-war modernist landscape architecture (Spens 1994), reason for which they were placed on the English Heritage's Register in 2010 (Registered Grade II). The Registration encourages appropriate protection of the Gardens and aims at increasing awareness of their social and ecological values. It is also a "material consideration" in the planning process. DBC is required to carefully consider the impact of any proposed development on the Gardens' special character as well as consult Historic England and the Hertfordshire Gardens Trust when reviewing planning applications affecting the Gardens.

The Gardens were restored between 2014 and 2017 by HTA Design LLT, under the initiative of $\mathrm{DBC}^{3}$. In line with the Registration requirements, the restoration adopted a conservative approach, rehabilitating most of the original layout, spatial configuration, and planting scheme. The process included intensive dredging and the restoration of the bridges and weirs and formal, constructed aquatic edges. The influence of the original design upon the current urban environment is still observable in the local community's uses and behaviours and evidenced by DBC and Hertfordshire County records. The restoration project was awarded the 2017 Heritage and Conservation Award from the UK Landscape Institute. Together with the English Heritage's Registration, the Award is a recognition of the Gardens' local importance and historic significance in terms of social-ecological values arising from the design of a public park functionally integrated with a water system. As observed in our fieldwork, engagement between the Gardens

\footnotetext{
${ }^{3}$ The restoration was funded by a $£ 2.4$ million grant from the Heritage Lottery Fund and the Big Lottery Fund as well as by an additional investment of $£ 1$ million from DBC.
} 
ecosystem and its socio-ecology occurs implicitly on a daily basis as shoppers and business people walk to and from their parked cars, through the Gardens. There is evidence of public security in the design, both within the adjacent children's park and around benches, viewing platforms, and other facilities.

\section{[Figure 3]}

Fig 3 Views of the Hemel Hempstead Water Gardens following the restoration: a) segment of the River Gade channel on the east side of the Gardens (alongside Waterhouse Street) with the islet, a viewing platform, and one of the three weirs (winter 2017); b) one of the alleys crossing the Flower Garden, with yew arches and planting scheme originally designed by Jellicoe's wife, Susan, and rehabilitated by HTA during the restoration (summer 2018).

\subsection{Governance Systems and Actors}

The Gardens management process is driven by two organisations, working separately and in conjunction: the DBC Parks and Green Spaces Department and the charity "The Friends of the Jellicoe Water Gardens" (FJWG). DBC provides the governmental element of public-space management through formal interventions working to a scheduled maintenance protocol. However, their annual budgets restrict the number of people employed within the management structure, as reported by DBC employees during our fieldwork. FJWG is a group of local volunteers supported by UK Heritage Lottery funding, who undertake voluntary and self-managing actions in the Gardens. Their aim is to "encourage the use and enjoyment of the Water Gardens", as well as to develop and maintain a "safe, beautiful and wildlife-rich environment" (FJWG 
Facebook page). FJWG present themselves as both "friends" and "custodians" of the Gardens. Their interventions include weed clearance, litter collection, and other maintenance activities, as well as holding community events. They were the initiators of an "Oral History" project, recording individuals' memories of the Gardens. They also launched a continued collective monitoring action for the protection of local species, involving the recording of the Gardens' avian, aquatics and mammal species (FJWG website). Through the restoration process, FJWG worked closely with DBC and HTA, assisting with the gardening and sharing knowledge of the Gardens' history and heritage value. Following the Gardens reopening in July 2017, FJWG continue hosting regular events (e.g. walks, wildlife days) inside and outside the Gardens for both locals and visitors. They also manage the local Community Garden, an educational space in which schools, local groups, and individuals can engage in gardening workshops, while increasing the community capacity to contribute to the Gardens' maintenance. The management practices undertaken by FJWG are mostly self-sustaining while some of the DBC facilities are used such as the Garden's meeting centre. Interactions between the two governmental and non-governmental parties are not formalised, and neither group is required to formally report to the other. In such a dynamic situation, a delicate balance is achieved by maintaining a flexible dialogue and interface between DBC and FJWG.

\section{Method and Materials}

\subsection{The SES framework}

The analysis of the Water Gardens urban common was conducted using the most updated version of the multilevel SES framework proposed by McGinnis and Ostrom 
(2014). Data from primary and secondary sources (as detailed below) were collected and compiled in order to inform our application of the framework in the Gardens case. As a starting point of the analysis, we identified the SES's four subsystems following McGinnis and Ostrom (2014). We identified the "Resource System" in the channelized segment of the river Gade as designed by Jellicoe and serving as the Gardens spine (Figure 1b). Our system's "Resource Units" (both natural and infrastructural) encompass the flow of water running in the channel, the flora and fauna inhabiting it (Figure 3b), as well as the infrastructure that allows the use of the Gade channel by men (weirs, bridges, and viewing platforms, Figure 3a). The "Actors" subsystem includes members of the FJWG group and their broader community, the landscape architects at HTA Design who led the restoration process, as well as representatives of the local authority directly involved in the management of the Gardens (DBC Parks and Green Spaces Department, Hertfordshire County Council). Finally, under "Governance Systems", we analysed both the governmental set of rules and non-governmental management models in place at the time our research was conducted (see Case Study). Following this stage, we determined the Interactions and Outcomes ("I-O nexus") characterising the Gardens' Action Situation (commoning actions in an urban water common). In line with our research question, we identified the following second-tier variables for our I-O nexus: "Self-organizing activities" (I7) for Interactions; "Social performance measures" $(\mathrm{O} 1)$ and "Ecological performance measures" $(\mathrm{O} 2)$ for Outcomes. Consistently with our understanding of urban water commons (see Introduction), by "social" and "ecological" "performance measures" we refer to the capacity of the commoning actions and self-organizing process to preserve the distinctive values of water systems for both human health and wellbeing and the 
functionality of urban ecosystems. Hence, among all second-tier variables proposed by McGinnis and Ostrom (2014), we concentrated only on those that, following our fieldwork, proved relevant to analyse the abovementioned four subsystems in light of the identified I-O nexus. Figure 4 presents all variables of the framework as identified by McGinnis and Ostrom (2014), as well as all the second-tier variables that were used in our case study (in bold), including a short description of the reasons for inclusion or exclusion.

\section{[Figure 4]}

Fig 4 First-tier and second-tier variables of the SES framework (McGinnis and Ostrom, 2014) excluding S and ECO, and reasons for inclusion/exclusion in the analysis of the Hemel Hempstead Water Gardens. All variables used in the analysis are marked in bold: Interaction and Outcome characterising the studied Action Situation (in red bold) and the four subsystems (in black bold). Self-organization-related variables according to Ostrom (2009) are identified with an asterisk; the variables added to describe first-tiers for which these second-tier variables were not relevant are marked in italic.

In Ostrom (2009), ten subsystems' second-tier variables are identified as related to selforganizing processes (marked with an asterisk in Figure 4), in the sense that they can positively or negatively affect the likelihood of actors to engage in self-organizing processes. Among these variables, we analysed those that, according to the results of our data collection, could help express the specificity of the self-organizing processes in the Gardens. Additional second-tier variables were only considered for the Governance Systems, since the only variable identified by Ostrom (2009) did not prove relevant to 
our case (see variable GS6 in Figure 4). Three second-tier variables were then added in order to better characterise governmental policy and "bottom-up" forms of governance in the management of the Gardens. These included "Monitoring and Sanctioning rules" (GS8) referring to the English Heritage Registration regulations, "Government organizations" (GS1) expressing the role of DBC in the restoration and managing regime, and "Nongovernment organizations" (GS2) including both "non-profit" (FJWG catalysing actions) and "profit" entities (e.g. HTA and impacts of restoration, and related actions by investors). In total, 16 second-tier variables were included in the analysis. S and ECO were not considered since our fieldwork focused only on the Gardens SES itself. Finally, we concentrated on two third-tier variables, "Networking activities" (I8) and "Monitoring activities" (I9) in order to better characterise the specific form of interactions at the centre of our research ("Self-organizing activities", second-tier variable I7). As discussed below, both activities were observed to consolidate the self-organizing processes and community-engagement among the Gardens' actors.

\subsection{Primary and secondary data}

Four complementary datasets were compiled in order to inform our application of the SES framework. Firstly, archived evidence on the design of the Gardens scheme was collected. This included original Jellicoe's drawings, reports and documents on the Gardens project from the Museum of English Rural Life (Landscape Institute Collection) and the Hertfordshire Archives and Local Studies Unit. Secondly, observations of green space interventions and actions by local actors and FJWG were made at different times (autumn and winter 2017, spring and summer 2018), supported 
by a collection of photographs. Thirdly, semi-structured interviews with four HTA landscape architects involved in the Gardens restoration were conducted in parallel to the consultation of HTA's documents on the design process (summer 2018). Finally, these data were triangulated with the results of three different kinds of qualitative analysis of data sourced from social media, including analysis of both Facebook and Twitter contents and user profiles (autumn 2018).

1) Topic modelling of contents posted by the FJWG Facebook community. Topic modelling is a text-mining technique frequently used for detecting main themes and semantic structures in large text bodies and unstructured collection of data (Blei, 2012). We applied this technique to analyse the contents of all posts published by FJWG on their Facebook page (events, photos, videos, links), and of all "public" posts (posts available to all Facebook users) shared by FJWG followers since the page was opened (2013). The following materials were analysed: 88 photo albums (containing a total of 1167 images of the Gardens and FJWG events), 35 event posts (regular monthly meetings and site visits), and 9 videos (5 of which on the restoration process), which were all shared by FJWG; 54 public posts that were shared by 27 of the 552 FJWG-Facebook followers. All words and sets of words in the posts were filtered and incorporated into a single topic. Complementarily, two different kinds of analysis of social-media user profiles were performed.

2) FJWG Facebook-community users. This analysis included a review of the users' profiles of all the 27 FJWG Facebook followers who shared public posts on the FJWG Facebook page. 
3) Mention network of Twitter users. The Twitter mention-network analysis (Kim et al. 2018) is a data mining technique used to express the connections between users (nodes) and a specific mention or hashtag (focal node) shared in a tweet. Since, in our case, FJWG have no official Twitter account and no "\#Hemel_Hempstead_Water_Gardens" hashtag was found, in the mention network we included any user sharing tweets containing all of the following words, hashtags, or location: "Hemel Hempstead Water Gardens". This included a total of 89 Twitter users. They were then distinguished into different user types, including individual, governmental and non-governmental, and this latter further divided into profit and non-profit (see GS1 and GS2 variables above). The results of both analyses of social media user profiles (Facebook and Twitter) allowed mapping the size and composition of the actor groups involved in the commoning actions (552 FJWG Facebook followers, 82 individual Twitter users, and 7 governmental and non-governmental - profit/non-profit - users). Data on the virtual community gathered around FJWG and the Water Gardens in general were used as proxies in our research, since no precise figure on the number of Gardens' users and other third parties involved in the commoning actions was available. Moreover, it was estimated that the official number of registered FJWG members was not representative of the (much higher) actual number of volunteers or individuals involved in the group activities.

\section{Results}

The results of the topic modelling of both FJWG posts and public posts shared by their online community (Figure 5) show that four main topics were addressed across all 
posts: (1) the Garden's flora and fauna and (2) its infrastructural elements (describing the Gardens' Resource Units), as well as (3) activities inside the Gardens, and (4) outside events organised by FJWG, the local authorities and other actors (describing the Interactions among actors). The topic words allowed gaining insights into Gardens' features and activities across different group ages in which the online community showed more interest (e.g. ducks, roses, planting, Christmas-meeting, playing-onplayground, build-bird-boxes), as well as actors' behaviours (e.g. proposing-help, sharing-pictures, complaining-about-litter) and scopes of the interactions among them (e.g. talk-about-heritage, asking-about-restoration, encounter-with-landscapearchitects). Transversal reading of the results also provided insights into the evolution of the scopes of the self-organising actions throughout the restoration process: before the construction works (e.g. launching-new-site, asking-about-interested-people), during them (e.g. play-area-consultation, walk-around-renovations), and following the reopening (e.g. guided-walk, gardening).

\title{
[Figure 5]
}

Fig 5 Topic modelling, based on qualitative content analysis of posts shared on the FJWG Facebook page, including both FJWG posts and Facebook-follower's public posts.

\author{
The review of the FJWG Facebook-community user profiles (Figure 6) showed that all \\ the 27 FJWG-Facebook followers sharing public posts on the FJWG page were \\ individual private actors. The majority of them were directly involved with FJWG or
}


other Hemel Hempstead public or non-profit institutions. For example, the user with most posts was Clare Richardson, chair of FJWG (biggest font in Figure 6).

\section{[Figure 6]}

Fig 6 Illustration of the FJWG Facebook-community user analysis based on number of public posts published by 27 FJWG Facebook-followers. The bigger the font, the higher the number of posts published.

Following the Twitter mention-network analysis (Figure 7), we found that the 89 identified Twitter users shared a total of 170 tweets, generating 27 replies, 118 retweets, and 49 likes. The main printed local newspaper The Gazette (featuring two accounts, @ thegazette_news and @ thebtgazette) posted the most tweets of all users (11 and 9 tweets respectively), providing regular information and updates on the different phases of the restoration process. The main governmental actors, Hertfordshire County Council (@DailyHERTS) and DBC (@DacorumBC), shared 9 tweets each, focusing on the restoration and associated participation process, as well as on investment opportunities. These tweets promoted both Councils' political and urban development views on the restoration process to possibly gain public consensus and strengthen synergies with developers. Additional 9 tweets were posted by a non-official Geoffrey Jellicoe account (@G_S_Jellicoe) managed by Lynda Harris, landscape architect and Jellicoe's greatniece, who shared images and information on the reopening of the Gardens. Two other individual-user accounts (@MarionGourd51 and @slv19photos) posted 7 and 5 tweets respectively, sharing images of the newly renovated Gardens. The remaining 111 tweets were posted by 82 individual-user accounts, including the designers involved in the 
restoration process promoting their professional work (@HTAdesignLLP and DominicColeDCLA). A real-estate investor account shared posts on the Gardens restoration process promoting Hemel Hempstead as a prime choice for business and attracting investors (@investHemel). Other accounts included amateur photographers sharing images of the Gardens' flora and fauna (@gmstringer and @andyhartleyuk), as well as accounts associated with automatic tweets generated by applications linking a location with its user (foursquare.com).

\section{[Figure 7]}

Fig 7 Illustration of the mention-network analysis of Twitter users based on number of published tweets including "Hemel Hempstead Water Gardens" as words, hashtags, or location. The bigger the font, the higher the number of posts published by the Twitter user. Colours identify different actor types. Red: governmental; cyan: no-profit nongovernmental; blue: profit non-governmental; green: individual.

\section{Discussion}

\subsection{Analysis of the SES framework second-tier variables}

The selected Resource System second-tier variables (Figure 4) allowed analysing the impact of distinctive characteristics of the Gardens water system on the local community engagement and self-organizing process. Starting from the size of our Resource System (RS3), we observed that the scale of the Gade channel remains moderate and partially self-contained $(615 \mathrm{~m}$ long), considering the overall size of the town ( 2350 hectares). The Gardens size ( 3.5 hectares) can be considered as of a moderated, intermediate scale compared to the smaller pocket parks and playgrounds in 
the Hemel Hempstead town centre, and the bigger woods and open fields located further North (where the channel crosses the suburban agricultural lands) and South (alongside the main branch of the river). Based on our field observations, we concluded that such a size, together with the channel's central location in the town (parallel to the main commercial road) (Figure 2a and 2b), can facilitate the internal cohesion of the local community (activities that are sustained within and by the community due to the presence of the Gardens, e.g. resting, social meetings, playing, observing the wildlife). In turn, this can favour the development of the self-organized commoning actions (Ostrom 2009). As demonstrated through previous research on commons (Chhatre and Agrawal 2009), a moderate-sized system can be more conducive to self-organization than small-scale or big-scale resource systems. These are less likely to generate selforganization, due to their inability to generate substantial flows (small systems) or due to higher maintenance costs (big systems).

The maintaining of the biological "productivity of the system" (RS5) was demonstrated to be a strong focus of the Gardens commoning actions, and the restoration works more particularly, as a means to maintain the ecological health and functionality of the water system. During the interviews, the restoration landscape architects affirmed having considered collaborations with the Environmental Agency and local biology and ecology experts as paramount in their work. By contrast, "economic productivity" didn't emerge as a focus of the commoning actions in our fieldwork, differently from other water-common case studies (Nagendra and Ostrom 2014) and Ostrom's original definition of the RS5 variable. No evidence of actors' intentions to gear the commoning activities to any productive or consumerist use (e.g. commercial fishing) was found in our data collection. Additionally, the restrictions resulting from the English Heritage's 
Grade II registration and the predominant recreational function which lies at the core of the management regime in place make it difficult to foresee any commercial exploitation of the Gade channel in the near future. Preservation of the system biological productivity involves "Monitoring activities" (I9, third-tier variable of "Selforganizing activities") through periodic observation of the Gardens' flora and fauna. This was one of the main focuses of the community-engagement activities, as demonstrated by the results of the topic modelling. Species identification and biodiversity counts promoted by FJWG were among the most popular topics on which the FJWG community shared posts on Facebook (Figure 5). Moreover, the gardens volunteers' monitoring system appeared to complement the measurements of water flows and river levels carried out at a UK Environment Agency's hydrometric station located a few miles upstream from the Gardens. As argued in other urban common studies (Langemeyer et al. 2018; Nagendra and Ostrom 2014), cooperation between non-governmental associations and governmental institutions can play a critical role in monitoring the ecological performance of a SES and ensuring that ecological values are maintained or improved over time. In the case of the Gardens, the development of collaborative monitoring activities across governmental and non-governmental actors could be envisioned in the future as a means to strengthen the local commoning actions while favouring the achievement of the social and ecological sustainability objectives pursued by all actor groups.

Moving to the Resource Units second-tier variables, the interviews with the landscape architects in the restoration team and the analysis of the posts on social media showed the strong attention paid by all actor groups (governmental and non-governmental, profit and non-profit) to the presence and values of the local species, as well as to the 
infrastructural elements designed to integrate the water system into the Gardens and to allow its recreational use (Figure 5). The flora and the infrastructural elements represent both "stationary" units, following analysis of the "mobility" second-tier variable (RU1). In Ostrom (2009), stationary units are associated with a higher likelihood of actors to self-organize and engage in commoning activities, since they require lower monitoring and managing costs than "mobile" resources. Among the mobile resource units, a stronger interest in units recurrently observed in the Gardens was shown by the repetition of the same names of birds, fish, and crustaceans in the posts (e.g. tits, kingfishers, ducks, geese, chubs, crayfish).

As for the "Governance Systems", the English Heritage's Registration proved a key determinant of the Gardens' self-organized management regime ("Monitoring and Sanctioning rules" GS8). The Registration has substantial impact on the commoning actions due to the associated conservation policy and regulation to which the Gardens are subject (see Case Study). Further, our fieldwork showed that the Gardens' actors have no full autonomy and rights to make and enforce their own rules collectively. Hence implementation of "collective-choice rules" (GS6) cannot be contemplated under the governance system currently in place. This makes a substantial difference with other urban commons in which greater local autonomy to establish resource management rules was observed to act as a catalyst for the commoning actions (Ostrom 2009; Chhatre and Agrawal 2009). In the analysis of the "Actors" subsystem, the results of the analysis of Facebook contents and users (Figure 5 and 6), showed the key role played by FJWG as the main catalyser of the commoning actions and facilitator of the self-organizing process (“Leadership" variable A5). FJWG shared 132 posts on their Facebook page (including 
1167 images) and additional 54 posts were shared on the same page by their online community (see Results). These posts reflect the role the group played in strengthening the commoning actions especially throughout three key moments in the Gardens recent history: before the construction works (e.g. posts about the launching of FJWG inviting people to join their group), during the restoration works (e.g. posts about the public consultation on the play area and construction site visits), and following the reopening (e.g. posts about guided walks and the launching of new activities in the Community Garden). The intensity of the exchanges on social media testifies FJWG's leadership position at these key moments as the result of both physical and virtual interaction with the local community. Moreover, FJWG's special position was enhanced by their knowledge of the water system ecological and social values ("Knowledge of SES" variable A7), which they shared during the several recreational and educational programmes organised inside and outside the Gardens (see topic words in Figure 5) and supported their recognition as leaders in the commoning actions. A clear ambition to share knowledge of the Gardens' social and ecological values was also shown by other private and public actors involved in the commoning, as manifested in the majority of posts published by the FJWG Facebook followers. Such posts concentrated mainly on the sharing of information on natural and infrastructural features of the Gardens water systems (local flora and fauna, facilities and structures, restoration works) and the learning of new skills (e.g. gardening, wood crafting workshops). According to Ostrom (2009), knowledge-gaining by actors can significantly enhance the social, ecological, and economic viability of the managed resource. Hence, both community leadership (A5) and knowledge-sharing (A7) proved an effective means to leverage community engagement and consolidate self-organization processes in the Gardens. 
Finally, the observed intense online activity and the sharing of Gardens-related posts on a regular basis by the FJWG profile and the other analysed Facebook and Twitter user profiles (see Results) demonstrated a strong general interest in the Resource System by the Actors ("Importance of the Resource", variable A8). However, qualitative indicators to monitor the actors' motivation (including actor groups other than FJWG) and the importance they attach to the Gardens' water system could not be identified during our data collection. As observed in similar urban common studies (Shah and Garg 2017, Follmann and Viehoff 2015), common interest in the same resource system by different stakeholder groups can positively impact the willingness of the actors to engage in commoning practices. The interviewed HTA landscape architects pointed repeatedly to the strong motivation shown by the actors and their attachment to the Gardens, which contributed to minimizing the organizational efforts required for communication campaigns and networking (see Interactions' third-tier variable "Networking activities" I8). The interviewees reported that the online community proved proactive in sharing information and getting engaged on a daily basis in the restoration process and in the activities connected to the reopening of the Gardens. Overall, the virtual networking among actors appeared to strengthen the collective actions and helped capitalize on complementary expertise and knowledge of the Gardens, while enhancing FJWG's leadership position.

\subsection{Limitations of social-media data analysis}

Analysis of social-media contents and user profiles provided valuable complementary data to archived evidence, field observations and semi-structured interviews (see 
Results). Moreover, it allowed revealing the significant role played by the online networking activities in the Gardens commoning actions.

However, methodologies for social-media data mining carries limitations, as stressed in the growing literature on the subject. These include, for example, the limited representation or exclusion of some actor groups, such as elderly, who are potentially less "visible" on social media than other groups (Trentham et al. 2015) but can be actively engaged in commoning actions. However, for case studies in Great Britain, it should be noted that a $17 \%$ increase in the number of social-media users aged 55-64 (from $30 \%$ to $47 \%$ ) and a $9 \%$ increase for users aged $65+$ (from $18 \%$ to $27 \%$ ) was observed between 2011 and 2018 (in parallel to an overall 20\% increase across all group ages, from $45 \%$ to $65 \%$ ), and this growing trend is predicted to continue in the future (ONS 2018 and 2011).

Another limitation in the analysis of social-media data consists of their relatively higher level of noise compared to other data mining techniques (Cobb 2015). In order to limit the noise level, more selective data-cleaning was required in our case study. Moreover, a higher level of subjectivity and more "human judgment" (Kim et al. 2018) was needed to interpret contents of posts or tweets and classify them in a comprehensive topicmodelling framework (e.g. coupling words, deducing broader topics from individual words or syntagma). In sum, data mining from social media needs more reliable analytical methods and more rigorous validation process (Kim et al. 2018). However, as in our case, social-media datasets can be used to triangulate data sourced through more traditional methods and can help test research hypotheses through the use of a wider spectrum of input data. 


\section{Conclusions and further research}

Our initial hypothesis was that water systems incorporated into urban spaces may foster commoning practices. For the purpose of assessing this hypothesis we analysed what might be the leverages for self-organization in urban water commons, representing one typology for SESs. The application of the Ostrom's SES framework in the study of Jellicoe's Hemel Hempstead Water Gardens supported the evaluation of distinctive natural and infrastructural features of the Gardens water system which may play a role in strengthening community engagement and the local self-organizing process. Our study was informed by evidence gathered across a broad spectrum of sources and analytical techniques. These include more traditional qualitative data collection and interpretation to data mining from social media. The online networking activities among different stakeholder groups appeared to play a key role in strengthening the collective actions and in consolidating the urban commoning practices in the Gardens. Moreover, they allowed the consolidation of a common reservoir of expertise and knowledge of the Gardens, while underpinning and strengthening the actors' common interest in the peculiar natural and infrastructural components of the Gardens: the flora and fauna inhabiting the channel, the construction works and their progress, the renovated bridges, viewing platforms, and other recreational facilities following the reopening. As reflected in the continued online communication on social media, the ubiquitous presence of the local charity across key moments of the Gardens' recent history (before and throughout the restoration process as well as following the reopening) was a critical component in the self-organizing process and allowed catalysing the recreational and knowledge-sharing activities on the water. 
Our analysis carries the limitations that are inherent to single case studies. A comparative study with other urban water commons with similar or contrasting characteristics is essential to generalise our findings and further test our hypothesis. However, any comparative effort should acknowledge the peculiarity of the Gardens case resulting from the international reputation of his landscape designer (Geoffrey Jellicoe) and the impact of the regulation restrictions introduce with the English Heritage Registration. It can be argued that this condition makes the Gardens more similar to an architectural "landmark" than to a conventional urban park (e.g. the restoration works received international coverage well beyond the Hemel Hempstead community and local press). The Gardens' fame and consequent visibility of the local community on the national and even international scene might have influenced the behaviour of some actor groups involved in the commoning actions. A cross-case study focusing on a more ordinary urban water common could, for example, support the validation or dismissal of this hypothesis. Moreover, a longitudinal study comparing the commoning actions and behaviours of the actor groups before and after the Gardens restoration could help ascertain to what extent this intervention had contributed to revamping the engagement of all parties (despite the "conservative" ambition reported by HTA in the interviews). Finally, returning to the emerging link between commoning and sustainability goals observed in other urban commons cases (see Introduction), our analysis provided little evidence of the impact of the local actions on the actual sustainability conditions and resilience of the Gardens SES. Last but not least, more evidence on the socioeconomic profiles of the actors involved (e.g. income levels and socio-demographics) is critical to properly investigate the social inclusivity of the groups and actions shaping the Gardens common. As in all SES studies, the variety of 
the social groups represented in commoning actions need further attention. This is essential to understand whether the adopted governance system is far-reaching enough for a resilient SES to be maintained and prosper over time.

\section{Acknowledgments}

The authors are grateful to Dacorum Borough Council - Parks and Green Spaces and to the HTA Design LLP members of staff (London Office) who agreed to be interviewed and shared internal reports and planning documents on the restoration of the Hemel Hempstead Water Gardens, as well as to the archivists at the Museum of English Rural Life (Landscape Institute Collection) and at the Hertfordshire Archives and Local Studies for their support during our research (Jellicoe's original drawings and reports on the Water Gardens project).

\section{Conflict of Interest}

The authors declare that they have no conflict of interest.

\section{References}

Acosta C, Ortega M, Bunsen T, Koirala BP, Ghorbani A (2018) Facilitating Energy Transition through Energy Commons: An Application of Socio-Ecological Systems Framework for Integrated Community Energy Systems. Sustainability 10(2): 366 http://doi.org/10.3390/su10020366

Blei, D.M. (2012) Probabilistic topic models. Communications of the ACM 55(4): 7784. https://doi.org/10.1145/3186262 
Chhatre A, Agrawal A (2009) Trade-offs and synergies between carbon storage and livelihood benefits from forest commons. Proceedings of the National Academy of Sciences 106(42): 17667-17670. https://doi.org/10.1073/pnas.0905308106

Colding J, Barthel J (2013) The potential of 'Urban Green Commons' in the resilience building of cities. Ecological Economics 86: 156-166.

https://doi.org/10.1016/j.ecolecon.2012.10.016

Colding J, Barthel S, Bendt P, Snep R, van der Knaap W, Ernstson H (2013) Urban green commons: Insights on urban common property systems. Global Environmental Change 23: 1039-1051. http://dx.doi.org/10.1016/j.gloenvcha.2013.05.006

Cobb WNW (2015) Trending now: Using big data to examine public opinion of space policy. Space Policy 32: 11-16. https://doi.org/10.1016/j.spacepol.2015.02.008

Cracknell D, Pahl S, White M, Depledge M (2018) Reviewing the role of aquaria as restorative settings: how subaquatic diversity in public aquaria can influence preferences, and human health and well-being. Human Dimensions of Wildlife, 23:5: 446-460. https://doi.org/10.1080/10871209.2018.1449039

Egerer M, Fairbairn M (2018) Gated gardens: Effects of urbanization on community formation and commons management in community gardens. Geoforum 96: 61-69. https://doi.org/10.1016/j.geoforum.2018.07.014

Elmqvist T, Folke C, Nyström M, Peterson G, Bengtsson J, Walker B, Norberg J (2003) Response diversity, ecosystem change, and resilience. Frontiers in Ecology and the Environment 1: 488-494. https://doi.org/10.1890/15409295(2003)001[0488:RDECAR]2.0.CO;2 
Follmann A, Viehoff V (2015) A green garden on red clay: creating a new urban common as a form of political gardening in Cologne, Germany. Local Environment 20(10): 1148-1174. http://dx.doi.org/10.1080/13549839.2014.894966

Frey UJ (2017) A synthesis of key factors for sustainability in social-ecological systems. Sustainability Science 12(4): 507-519. https://doi.org/10.1007/s11625-016$\underline{0395-\mathrm{Z}}$

Jellicoe GA (1947). The Report accompanying a plan for Hemel Hempstead New Town. Prepared for the Hemel Hempstead Development Corporation, 3rd June 1947. Jellicoe, Ballantyne \& Coleridge Chartered Architects (1960). Specification of works to be executed, plants and materials to be provided, for the planting of Water Gardens at Hemel Hempstead, under the supervision of, and to the satisfaction of, Messrs. Jellicoe, Balantyne and Coleridge. April 1960.

Kim HJ, Chae BK, Park SB (2018) Exploring public space through social media: an exploratory case study on the High Line New York City. Urban Design International 23(2): 69-85. https://doi.org/10.1057/s41289-017-0050-Z

Langemeyer J, Camps-Calvet M, Calvet-Mir L, Barthel S, Gómez-Baggethun E (2018) Stewardship of urban ecosystem services: understanding the value(s) of urban gardens in Barcelona. Landscape and Urban Planning 170: 79-89. http://dx.doi.org/10.1016/j.landurbplan.2017.09.013

Marshall G (2008) Nesting, subsidiarity, and community-based environmental governance beyond the local. International Journal of the Commons 2(1): 75-97. http://doi.org/10.18352/ijc.50

McGinnis MD, Ostrom E (2014) Social-ecological system framework: initial changes 
and continuing challenges. Ecology and Society 19(2): 30.

http://dx.doi.org/10.5751/ES-06387-190230

Mundoli S, Manjunath B, Nagendra H (2015) Effects of urbanisation on the use of lakes as commons in the peri-urban interface of Bengaluru, India. International Journal of Urban Sustainable Development 7 (1): 89-108.

https://doi.org/10.1080/19463138.2014.982124

Murphy A, Enqvist JP, Tengö M (2019) Place-making to transform urban socialecological systems: insights from the stewardship of urban lakes in Bangalore, India. Sustainability Science 14(3): 607-623. https://doi.org/10.1007/s11625-019-00664-1 Nagendra H, Ostrom, E (2014) Applying the social-ecological system framework to the diagnosis of urban lake commons in Bangalore, India. Ecology and Society 19(2): 67. http://dx.doi.org/10.5751/ES-06582-190267

ONS (Office for National Statistics, UK) (2018), Internet access - households and individuals, Great Britain. Published 8 August 2018. Available at:

https://www.ons.gov.uk/peoplepopulationandcommunity/householdcharacteristics/hom $\underline{\text { einternetandsocialmediausage/datasets/internetaccesshouseholdsandindividualsreferenc }}$ etables Accessed 4 July 2019

ONS (Office for National Statistics, UK) (2011), Internet access - households and individuals, Great Britain. Available at:

https://www.ons.gov.uk/peoplepopulationandcommunity/householdcharacteristics/hom $\underline{\text { einternetandsocialmediausage/datasets/internetaccesshouseholdsandindividualsreferenc }}$ etables Accessed 4 July 2019 
Ostrom E (1990) Governing the Commons. The Evolution of Institutions for Collective Action. Cambridge University Press, Cambridge.

Ostrom E (2007) A diagnostic approach for going beyond panaceas. Proceedings of the National Academy of Sciences 104 (39):15181-15187.

http://dx.doi.org/10.1073/pnas.0702288104

Ostrom E (2008) The challenge of common pool resources. Environment 50: 8-21. https://doi.org/10.3200/ENVT.50.4.8-21

Ostrom E (2009) A general framework for analyzing sustainability of social-ecological systems. Science 325:419-422. http://dx.doi.org/10.1126/science.1172133

Ostrom E, Ahn TK (2003) Introduction to Foundations of social capital. Edward Elgar, Cheltenham, UK, pp xi-xxxix

Partelow S (2016) Coevolving Ostrom's social-ecological systems (SES) framework and sustainability science: four key co-benefits. Sustainability Science 11(3): 399-410. https://doi.org/10.1007/s11625-015-0351-3

Perrotti D, Iuorio O (2018) Green Infrastructure in the Space of Flows: An Urban Metabolism Approach to Bridge Environmental Performance and User's Wellbeing. In Lemes de Oliveira, F. and Mell, I. (eds.), Planning Cities with Nature: Theories, strategies and methods. Dordrecht: Springer, pp 265-277. https://doi.org/10.1007/978-3$\underline{030-01866-5 \quad 18}$

Petrescu D, Petcou C, Baibarac C (2017) Co-producing commons-based resilience: lessons from R-Urban. Building Research \& Infromation 44(7): 717-736. http://dx.doi.org/10.1080/09613218.2016.1214891 
Radywyl N, Biggs C (2013) Reclaiming the commons for urban transformation. Journal of Cleaner Production 50: 159-170. http://dx.doi.org/10.1016/j.jclepro.2012.12.020 Rodgers CP, Straughton E, Winchester AJL, Pieraccini M (2011) Common Land as a Contested Resource. In id. (eds.) Contested Common Land. Environmental Governance Past and Present. London: Routledge, p. 1-16.

Shah A, Garg A (2017) Urban commons service generation, delivery, and management: A conceptual framework. Ecological Economics 135: 280-287.

http://dx.doi.org/10.1016/j.ecolecon.2016.12.017

Spens M (1994) The Complete Landscape Designs and Gardens of Geoffrey Jellicoe. Thames \& Hudson, London.

Trentham B, Sokoloff S, Tsang A, Neysmith S (2015) Social media and senior citizen advocacy: an inclusive tool to resist ageism? Politics, Groups, and Identities, 3(3): 558571. https://doi.org/10.1080/21565503.2015.1050411 


\title{
Do-Can water systems foster-enhance commoning practices? Analysing leverages for self-organization in urban water commons as social-ecological systems.
}

\author{
Abstract \\ Research into urban commons has gained momentum in recent years. This article \\ concentrates on the concept and analysis of urban water commons as social-ecological \\ systems, which receive a less prominent focus in the literature than other commoning \\ practices. In the light of the distinctive social and ecological values of water for both \\ ecosystem health and human wellbeing and sociability, we argue that the presence of \\ water systems can foster enhance-stakeholder engagement and leverage self- \\ organization in urban commons. We test our hypothesis in a dynamically-evolving \\ urban water common: the recently restored Geoffrey Jellicoe's Water Gardens in Hemel \\ Hempstead, England. We apply Elinor Ostrom's multilevel diagnostic tool, the "Social- \\ Ecological System framework", to analyse the characteristics of the Gardens water \\ system and their impact on the self-organizing process undertaken by the local \\ community. Our application is supported by collection of primary and secondary data, \\ including Jellicoe's design archived evidence, field observation data, in-depth \\ interviews with key stakeholders, as well as data mining from social media (topic \\ modelling of Facebook posts, review of Facebook user profiles, and Twitter mention- \\ network analysis). $\Theta$ Through our results, we identify a broad spectrum of characteristics \\ of the Gardens urban water common show that the local self-organization dynamics are \\ can catalyse be positively influenced-the local self-organization dynamics by a broad \\ spectrum of characteristics of the Gardens urban water common. Theseis include the \\ leadership and entrepreneurial capacityposition of a specific non-governmental actor
}


group with knowledge and expertise on water ecosystems; active engagement of the local population across age groups in recreational activities on the water; communitybuilding through expertise and knowledge sharing on the peculiar natural and infrastructural components of the Gardens water systems; and, finally, continued online networking and eommunication ons social media communication among different stakeholder groups on water-related activities.

\section{Keywords}

Green and Blue Infrastructure, Social-Ecological System Framework, Governance Systems, Water Systems Management, Big Data, Social Media.

\section{Introduction}

\subsection{Urban commons as social-ecological systems}

The concept of "urban common" has in recent years gained significant success in interdisciplinary studies discussing a broad variety of social and ecological dynamics occurring in urban spaces. Within the scope of this article, we define "urban commons" as public spaces contained within urban regions in which communities of individuals self-organize in order to manage a resource collectively (e.g. water, crops, or simply land). Complementarily, the expression "commoning actions" or "commoning practices" ean be used to-refer to the social and institutional practices that are required to manage a common-pool resource and are grounded on bottom-up governance systems (Petrescu et al. 2017). Commoning actions and practices are frequently undertaken on a voluntaristic basis through interactions amongst individuals who share 
an identity, leading to dynamic forms of self-management alternatively or in conjunction with governmental management regimes.

The popularity of the concept in both social and environmental sciences has been leveraged by a growing interest in Elinor Ostrom's $(1990,2008)$ work and intellectual legacy promoting an understanding of urban commons as social-ecological systems (SESs) (e.g. Radywyl and Biggs 2013; Colding et al. 2013; Colding and Barthel 2013; Egerer and Fairbairn 2018). A Scopus search conducted in January 2019 showed that, following Ostrom's pivotal work in 1990, 182 articles and book chapters containing "urban commons" in the title, abstract and-or keywords were published in English between 1995 and 2018 (of which, 142 published between-from 2013 and-to 2018).

RecentA fewSeveral urban common studies in western countries and the Global South (e.g. e.g.-Murphy et al. 2019; Petrescu et al. 2017; Follman and Viehoff 2015; Mundoli et al. 2015; )ease studies (Petreseu et al. 2017; Mundoli et al. 2015; Radywyl and Biggs 2013) show aA clear convergence between commoning practices and overall sustainability concerns, or between commoning and resilient strategies, can be observed in recent case studies, making urban commons a compelling subject and fertile ground for sustainability science.- Urban sustainability and resilience have emerged as a focus across urban commons in western countries and the Global South.o.g. Murphy 2019; Petresen 2017; Follmand Viehoff 2015; Mundian 2015)-In these studies, sIn these contexts, sustainability concerns and collective aspirations to socialecological resilience $/$ sustainability and resilience ean be interpreted considered as aprovide a broader umbrella topic embracing the sembracing a more traditionalfocus on equitable access and use of lands which has traditionally been traditionally at the 
heart of commons' research ${ }^{1}$ (Ostrom 1990) in urban common research. Some authors

argue that Sself-organization dynamics and shared interests in common-resource management among actors can support the development of new behavioural, cultural and structural configurations which are primary drivers of sustainable urban transformation over time (Radywyl and Biggs 2013; Radywyl and Biggs 2013; Marshall 2008). Hence urban commons have been studied as vectors of new bottom-up forms of sustainability and testing grounds for "co-produced resilience processes" (Petrescu et al. 2017). These multiple entanglements make urban commons a compelling subject and fertile ground for sustainability science.

\subsection{Knowledge gap and research question: urban water commons}

Water systems have provided a strong focus in Ostrom's work on commons and related self-organizing processes (Ostrom 1990). However, urban water commons have received less attention in contemporary literature than other urban commoning practices. When the abovementioned Scopus search (1995-2018) is streamlined using the "urban commons AND water" criterion, outputs are reduced down to six.

This knowledge gap is particularly compelling once we take into consideration the distinctive values of water systems for both human health and the functionality of urban ecosystems (Perrotti and Iuorio 2018). As demonstrated by a growing portfolio of research, these values are of both social and ecological nature and result from the specific characteristics of water, its essential life functions for humans and ecosystems,

\footnotetext{
${ }^{1}$ Equitable access is a traditional and essential element of commoning practices in the UK since the 16th century. This involved access for all local people to common grazing, tethering and livestock sustenance on a designated land. More recently, the Commons Act 2006 introduced reforms to the property rights regime for common land, which provided a more equitable basis for land-resource access (Rodgers et al., 2011).
} 
and the relationship that communities establish with it. For example, the presence of water can contribute to enhancing human interactions in urban public spaces as well as foster actual and perceived health and wellbeing of individuals (Cracknell et al. 2018; Murphy et al. 2019). Aquatic organisms can assist in maintaining water quality= and aquatic species diversity can increase functional robustness and biodiversity of other species, sustaining the robustness of the overall ecosystem (Elmqvist et al. 2003). In light of these distinctive social-ecological values of water and their positive influence on healthier and more resilient SESs, emrthe research presented in this article aims to explores whether and how the presence of water systems in urban public spaces can enhance-foster community engagement and leverage self-organization in urban commons. Our underlying hypothesis is that the common use and collective management of water systems in urban environments can enhanee promote the internal cohesion of communities sharing a resource and, as a consequenceconsequently, can leverage urban commoning practices.

For the purpose of addressing our research question, we use the Hemel Hempstead Water Gardens in the Borough of Dacorum, Hertfordshire, England, as a case study. We apply the multilevel SES framework proposed by Elinor Ostrom (2008) as a method to analyse our case and test our working hypothesis, supported by a collection of primary and secondary data. The Water Gardens were designed by landscape architect Geoffrey Jellicoe (1957-1959), founding member of the International Federation of Landscape Architects and of the UK Landscape Institute. They were placed on the English Heritage's Register of Parks and Gardens of Special Historic Interest (2010), and, under the initiative of Dacorum Borough Council, recently restored by the practice HTA Design LLP, London (2014-2017). The Gardens social-ecological values are enhanced 
both by design attributes and elements of local governance. Moreover, the clear identification with water as manifested in their name makes the Gardens a particularly relevant case for evaluating how water systems can enhance-foster urban commoning practices.

The article is structured as follows. In the "Background", section-fundamental principles of the Ostrom's SES framework are introduced. In the "Case Study", we present the main characteristics of the Water Gardens urban common - -which guided the application of the SES framework. In "Method and Materials", Then, we describe the method we employed to adapt and apply the framework to our case study as well as the primary and secondary data collected to inform our application-In "Results". Subsequently, wand we present the outcomes of our case study and data collection. Finally, in the "Diseussion" we discuss key characteristics of the Gardens' water system which, following the framework application, were demonstrated to enhanceidentified as catalyst for the local commoming practices and self-organizing process.

\section{Background}

Ostrom's $(2007,2009)$ multilevel, nested SES framework (amended by McGinnis and Ostrom 2014) was conceived as a tool to study the relationships among the multiple levels that compose a common, while providing the basis for shared diagnosis and understanding of commons among disciplines. Through TheIts application of the framework as a diagnostic tool, it is possible tocan support the identification of $y$ the

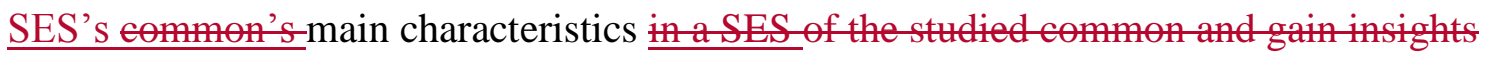


inte-and provide insights into modes of interaction and self-organizing processes among actors involved in the collective management of the common-pool resource. In the framework, firstly SESs are analysed based on the description of four main subsystems composing the system, as well as by any direct and indirect influence each subsystem has on the others (Figure 1). The subsystems are: (i) Resource Systems (e.g. a water system); (ii) Resource Units (natural and infrastructural components of the resource system); (iii) Governance Systems (governmental and non-governmental policy and measures for the management of the resource system); and (iv) Actors ${ }^{2}$ (individuals or organizations using the resource system for different purposes and any other involved third parties). Secondly, the peculiar character of each SES is defined through the identification of an "Action Situation" (Figure 1). The concept of "Action Situation" refers to the generation of a set of specific outcomes in a SES through multiple forms of interactions among the actors (e.g. "commoning actions"). Hence the Action Situation of a SES is defined by the interlinks between the identified Interactions and Outcomes (named "Interactions-Outcomes (I-O) nexus") (McGinnis and Ostrom 2014). The four abovementioned subsystems and the Interactions and Outcomes defining the Action Situations represent the first-tier variables of the SES framework. They are analysed based on their mutual influences and all exogenous influences they receive from other ecosystems (ECO) or external social, economic and political settings (S).

\footnotetext{
${ }^{2}$ In the original version of the SES framework proposed by Ostrom $(2007,2009)$ the "Actors" first-tier category was named "Users". It has been afterwards generalised to "Actors" by McGinnis and Ostrom (2014), on the basis that the framework should also include the behaviours of third parties not directly using the resource systems and units., and $₫$ This amendment is recommended for any future use.
} 
Fig 1 First-tier variables (the four Subsystems and the Interactions-Outcomes nexus) composing the Social-Ecological System framework, and direct and feedback links among them (solid/dotted arrows). Adapted from: McGinnis and Ostrom 2014, p.4.

Each first-tier variable is decomposed into a range of second-tier variables, which can be used to describe the Interactions, Outcomes and Subsystems, and are, in turn, decomposed into third-tier variables. Second- and third-tier variables that are relevant to the studied SES can be identified and organized based on fieldwork and data collection. Recent research has demonstrated that the framework can support the implementation of transdisciplinary agendas in sustainability science and, faveuringacilitate the integration of scientific knowledge and easier-communication of scientific knowledge to decision-makers and practitioners (Partelow 2016). Its use in case study research can also contribute to expanding the applicability of sustainability agendas to a wider range of concepts and systems (Frey 2017). When applied in urban contexts, the framework can help unfold the urban sustainability aspects that are embedded within commoning practices, and to-promote an understanding of analyse-urban commons as potential vectors of socially and environmentally sustainable practices in cities or metropolitan regions. For example, applications of the SES framework in urban contexts include analysis of changes from community-based governance to state management regimes of urban lakes commons (Nagendra and Ostrom 2014), as well as analysis of development process and governance systems of Integrated Community Energy Systems (Acosta et al. 2018). As these works demonstrate, the use of the framework can allow identifying SES characteristics and stakeholder dynamics fostering social-ecological resilience and 
values, as well as help evaluate the challenges stakeholders face in achieving sustainability objectives.

\section{Case study}

\subsection{Resource System and Resource Units}

The Water Gardens are situated in the centre of Hemel Hempstead (population of 94,932 - 2011 census), located $39 \mathrm{~km}$ northwest of London, under the jurisdiction of Dacorum Borough Council (DBC). Hemel Hempstead was developed in 1947 under the British Government "New Towns Programme". Areas of land were designated for the construction of a "new town" in order to respond to the severe housing shortage in London after World War II. The Gardens have a size of approximately 3.5 hectares, extending on both sides of a $615 \mathrm{~m}$ long north-branch channelized section of the River Gade. They have a north-south length of 615 metres and a maximum east-west width of approximately 50 metres. They are bounded to the east by a commercial street with various public facilities, and to the west by a high load, suburban link road and a twostorey car park-_(Figure 2a-b). The Gardens are open to the surrounding urban space, allowing for full accessibility during day and night from pedestrian entrances and bridges connecting them to the town centre.

\section{[Figures 2a-2b]}

Fig 2 Aerial views of: a) the Hemel Hempstead Water Gardens, showing the surrounding commercial Waterhouse Street (east side), the suburban-link road Leighton Buzzard Road (west), Combe Street (north), and Mill End Road (south); b) location of 
the Water Gardens in the Hemel Hempstead town centre. The dotted lines represent the Gardens' edges and the administrative boundary of the Hemel Hempstead town.

The Gardens initially represented a key component of Jellicoe's (unbuilt) Masterplan for the Hemel Hempstead "new town", in which they served as the core recreational space at the heart of the town centre (Jellicoe, 1947). One of the main goals of the scheme was to deliver an important socio-ecological focus, provideing leisure, and utility factors-as well as social, economic, welfare and ecologicalenvironmental benefits based onto the community, aligning with the aspirations of the new town programme 's needs, and as well as utility factors-(Jellicoe et al. 1960). Jellicoe's design vision aligned with the concepts of inclusivity for all societal actors and with the aspirations of the new town programme (Jellicee 1947). A water-engineering project of moderate complexity was undertaken to create the Gardens alongside the Gade channel, including diverting a relatively fast flowing, small chalk stream into the new town centre. The stream water combines with the water from the Gade and collects into artificial, landscaped shallow lakes. The Gardens follow a linear layout and have been designed as a collection of individual gardens, separated by roadways and defined by distinct functions. They have a north-south length of 615 metres, a maximum east-west width of approximately 50 metres, and are longed by a pedestrian path on the west side of the landscaped river. The river channel is crossed by four bridges, three southflowing weirs and raised viewing platforms, whilst and an artificial islet in the middle of the channel-is located on the east side (Figure 3a). The Gardens follow a linear layout and have been designed as a collection of individual gardens defined by distinct functions. Grasses, water lilies, and other water plant species punctuate the water's edge 
for most of the Gardens' length, while the multi-storey car park is sereened by informal tree planting and shrubbery. An area of more formatornamental planting_(“-Flower Garden") with flowers and a shrubbery crossed by a grid of regular paths was laid out on the west side of the channel,, including the Flower Garden-(ornamental garden Figure 3b) alengside a fountain peot(Jellicoe et al. 1960). The Gardens are recognized as an exemplary case of post-war modernist landscape architecture (Spens 1994), reason for which they were placed on the English Heritage's Register in 2010 (Registered Grade II). The Registration encourages appropriate protection of the Gardens and aimsing at increasing awareness of their social and ecological values. It is also a "material consideration" in the planning process. DBC is required to carefully consider the impact of any proposed development on the Gardens' special character as well as consult Historic England and the Hertfordshire Gardens Trust when reviewing planning applications affecting the Gardens.

The Gardens were restored between 2014 and 2017 by HTA Design LLT, under the initiative of $\mathrm{DBC}^{3}$. In line with the Registration requirements, the restoration adopted a conservative approach, rehabilitating most of the original layout, spatial configuration, and planting scheme. The process included intensive dredging and the restoration of the bridges and weirs and formal, constructed aquatic edges. The influence of the original design upon the current urban environment is still observable in the local community's uses and behaviours and evidenced by DBC and Hertfordshire County records. The restoration project was awarded the 2017 Heritage and Conservation Award from the UK Landscape Institute. Together with the English Heritage's Registration, the Award is a recognition of the Gardens' local importance and historic significance in terms of

\footnotetext{
${ }^{3}$ The restoration was funded by a $£ 2.4$ million grant from the Heritage Lottery Fund and the Big Lottery Fund as well as by an additional investment of $£ 1$ million from DBC.
} 
social-ecological values arising from the design of a public park functionally integrated with a water system. As observed in our fieldwork, engagement between the Gardens ecosystem and its socio-ecology occurs implicitly on a daily basis as shoppers and business people walk to and from their parked cars, through the Gardens. There is evidence of public security in the design, both within the adjacent children's park and around benches, viewing platforms, and other facilities.

\section{[Figure 3]}

Fig 3 Views of the Hemel Hempstead Water Gardens following the restoration: a) segment of the River Gade channel on the east side of the Gardens (alongside Waterhouse Street) with the islet, a viewing platform ${ }_{2}$ and one of the three weirs (winter 2017); b) one of the alleys crossing the Flower Garden, with yew arches and planting scheme originally designed by Jellicoe's wife, Susan, and rehabilitated by HTA during the restoration (summer 2018).

\subsection{Governance Systems and Actors}

The Gardens management process is driven by two organisations, working separately and in conjunction: the DBC Parks and Green Spaces Department and the charity "The Friends of the Jellicoe Water Gardens" (FJWG). DBC provides the governmental element of public-space management through formal interventions working to a scheduled maintenance protocol. However, their annual budgets restrict the number of people employed within the management structure, as reported by DBC employees during our fieldwork. FJWG is a group of local volunteers supported by UK Heritage Lottery funding, who undertake voluntary and self-managing actions in the Gardens. 
Their aim is to "encourage the use and enjoyment of the Water Gardens", as well as to develop and maintain a "safe, beautiful and wildlife-rich environment" (FJWG Facebook page). FJWG present themselves as both "friends" and "custodians" of the Gardens. Their interventions include organising working parties for-weed clearance, litter collection, and other maintenance activities, as well as holding community events. They were the initiators of an "Oral History" project, recording individuals' memories of the Gardens. They also launched a continued collective monitoring action for the protection of local species, involving the recording of the Gardens' avian, aquatics and mammal species (FJWG website). Through the restoration process, FJWG worked closely with DBC and HTA, assisting with the gardening and sharing knowledge of the Gardens' history and heritage value. Following the Gardens reopening in July 2017, FJWG continue hosting regular events (e.g. walks, wildlife days) inside and outside the Gardens for both locals and visitors. They also manage the local Community Garden, an educational space in which schools, local groups, and individuals can engage in gardening workshops, while increasing the community capacity to contribute to the Gardens' maintenance. The management practices undertaken by FJWG are mostly self-sustaining while some of the DBC facilities are used such as the Garden's meeting centre. Interactions between the two governmental and non-governmental parties are not formalised, and neither group is required to formally report to the other. In such a dynamic situation, a delicate balance is achieved by maintaining a flexible dialogue and interface between DBC and FJWG.

\section{Method and Materials}

\subsection{The SES framework}


The analysis of the Water Gardens urban common was conducted using the most updated version of the multilevel SES framework proposed by McGinnis and Ostrom (2014). Data from primary and secondary sources (as detailed below) were collected and compiled in order to inform our application of the framework in the Gardens case. As a starting point of the analysis, we identified the SES's four subsystems following McGinnis and Ostrom (2014). We identified the "Resource System" in the channelized segment of the river Gade as designed by Jellicoe and serving as the Gardens spine (Figure 1b). Our system's “Resource Units” (both natural and infrastructural) encompass the flow of water running in the channel, the flora and fauna inhabiting it (Figure 3b), as well as the infrastructure that allows the use of the Gade channel by men (weirs, bridges, and viewing platforms, Figure 3a). The "Actors" subsystem includes members of the FJWG group and their broader community, the landscape architects at HTA Design having-who participated-led in the restoration process, as well as representatives of the local authority directly involved in the management of the Gardens (DBC Parks and Green Spaces Department, Hertfordshire County Council). Finally, under "Governance Systems", we analysed both the governmental set of rules and non-governmental management models in place in the Gardens-at the time our research was conducted (seeef. "Case Studysection"). Following this stage, we determined the Interactions and Outcomes ("I-O nexus") characterising the Gardens' Action Situation (commoning actions in an urban water common). In line with our research question, we identified the following second-tier variables for our I-O nexus: "Self-organizing activities" (I7) for Interactions; "Social performance measures" (O1) and "Ecological performance measures" (O2) for Outcomes. Consistently with our understanding of urban water commons (seeef. Introduction), by "social” and 
"ecological" "performance measures" we refer to the capacity of the commoning actions and self-organizing process to preserve the distinctive values of water systems for both human health and wellbeing and the functionality and robustness-of urban ecosystems. Hence, among all second-tier variables proposed by McGinnis and Ostrom (2014), we concentrated only on those that, following our fieldwork, proved relevant to analyse the abovementioned four subsystems in light of the identified I-O nexus. Figure 4 presents all variables of the framework as identified by McGinnis and Ostrom (2014), as well as all the second-tier variables that were used in our case study (in bold), including a short description of the reasons for inclusion or exclusion.

\section{[Figure 4]}

Fig 4 First-tier and second-tier variables of the SES framework (McGinnis and Ostrom, 2014) excluding S and ECO, and reasons for inclusion/exclusion in the analysis of the Hemel Hempstead Water Gardens. All variables used in the analysis are marked in bold: Interaction and Outcome characterising the studied Action Situation (in red bold) and the four subsystems (in black bold). Self-organization-related variables according to Ostrom (2009) are identified with an asterisk; the variables added to describe first-tiers for which these second-tier variables were not relevant are marked in italic.

In Ostrom (2009), ten subsystems' second-tier variables are identified as related to selforganizing processes (marked with an asterisk in Figure 4), in the sense that they can positively or negatively affect the likelihood of actors to engage in self-organizing processes. Among these variables, we analysed those that, according to the results of our data collection, could help express the specificity of the self-organizing processes in 
the Gardens. Additional second-tier variables were only considered for the Governance Systems, since the only variable identified by Ostrom (2009) did not prove relevant to our case (ef.see variable GS6 in Figure 4). Three second-tier variables were then added in order to better characterise governmental policy and "bottom-up" forms of governance engagementin the management of the Gardens. These included "Monitoring and Sanctioning rules" (GS8) referring to the English Heritage Registration regulations, "Government organizations" (GS1) expressing the role of DBC in the restoration and managing regime, and "Nongovernment organizations" (GS2) including both "non-profit" (FJWG catalysing actions) and "profit" entities (e.g. HTA and impacts of restoration, and related actions by finvestors). In total, 16 secondtier variables were included in the analysis. S and ECO were not considered since our fieldwork focused only on the Gardens SES itself. Finally, we concentrated on two third-tier variables, "Networking activities" (I8) and "Monitoring activities" (I9) in order to better characterise the specific form of interactions at the centre of our research ("Self-organizing activities", second-tier variable I7). As discussed below, both activities were observed to consolidate the self-organizing processes and communityengagement among the Gardens' actors.

\subsection{Primary and secondary data}

Four complementary datasets were compiled in order to inform our application of the SES framework. Firstly, archived evidence on the design of the Gardens scheme was collected. This included original Jellicoe's drawings, reports and documents on the Gardens project from the Museum of English Rural Life (Landscape Institute Collection) and the Hertfordshire Archives and Local Studies Unit. Secondly, 
observations of green space interventions and actions by local actors and FJWG were made at different times (autumn and winter 2017, spring and summer 2018), supported by a collection of photographs. Thirdly, semi-structured interviews with four HTA landscape architects involved in the Gardens restoration were conducted in parallel to the consultation of HTA's documents on the design process (summer 2018). Finally, these data were triangulated with the results of three different kinds of qualitative analysis of data sourced from social media, including analysis of both Facebook and Twitter contents and user profiles (autumn 2018).

\section{1) Topic modelling of contents posted by the FJWG Facebook community. Topic} modelling is a text-mining technique frequently used for detecting main themes and semantic structures in a-large text bodiesy and unstructured collection of data (Blei, 2012). We applied this technique to analyse the contents of all posts published by FJWG on their Facebook page (events, photos, videos, links), and of all "public" posts (posts available to all Facebook users) shared by FJWG followers since the page was opened (2013). The following materials were analysed: 88 photo albums (containing a total of 1167 images of the Gardens and FJWG events), 35 event_-posts (regular monthly meetings and site visits), and 9 videos ( 5 of which on the restoration process), which were all shared by FJWG; 54 public posts that were shared by 27 of the 552 FJWG-Facebook followers. All words and sets of words in the posts were filtered and incorporated into a single topic. Complementarily, two different kinds of analysis of social-media user profiles were performed. 
2) FJWG Facebook-community users. This analysis included a review of the users' profiles of all the 27 FJWG Facebook followers who shared public posts on the FJWG Facebook page.

3) Mention network of Twitter users. The Twitter mention-network analysis (Kim et al. 2018) is a data mining technique used to express the connections between users (nodes) and a specific mention or hashtag (focal node) shared in a tweet. Since, in our case, FJWG have no official Twitter account and no "\#Hemel_Hempstead_Water_Gardens" hashtag was found, in the mention network we included any user sharing tweets containing all of the following words, hashtags, or location: "Hemel Hempstead Water Gardens". This included a total of 89 Twitter users. They were then distinguished into different user types, including individual, governmental and non-governmental, and this latter further divided into profit and non-profit (ef.see GS1 and GS2 variables above). The results of both analyses of social media user profiles (Facebook and Twitter) allowed mapping the size and composition of the actor groups involved in the commoning actions (552 FJWG Facebook followers, 82 individual Twitter users, and 7 governmental and non-governmental - profit/non-profit - users). Data on the virtual community gathered around FJWG and the Water Gardens in general were used as proxies in our research, since no precise figure on the number of Gardens' users and other third parties involved in the commoning actions was available. Moreover, it was estimated that the official number of registered FJWG members was not representative of the (much higher) actual number of volunteers or individuals involved in the group activities. 


\section{Results}

The results of the topic modelling of both FJWG posts and public posts shared by their online community (Figure 5) show that four main topics were addressed across all posts: (1) the Garden's flora and fauna and (2) its infrastructural elements (describing the Gardens' Resource Units), as well as (3) activities inside the Gardens, and (4) outside events organised by FJWG, the local authorities and other actors (describing the Interactions among actors). The topic words allowed gaining insights into Gardens' features and activities across different group ages in which the online community showed more interest (e.g. ducks, roses, planting, Christmas-meeting, playing-onplayground, build-bird-boxes), as well as actors' behaviours (e.g. proposing-help, sharing-pictures, complaining-about-litter) and scopes of the interactions among them (e.g. talk-about-heritage, asking-about-restoration, encounter-with-landscapearchitects). Transversal reading of the results also provided insights into the evolution of the scopes of the self-organising actions throughout the restoration process: before the construction works (e.g. launching-new-site, asking-about-interested-people), during them (e.g. play-area-consultation, walk-around-renovations), and following the reopening (e.g. guided-walk, gardening).

\section{[Figure 5]}

Fig 5 Topic modelling, based on qualitative content analysis of posts shared on the FJWG Facebook page, including both FJWG posts and Facebook-follower's public posts. 
[Figure 6]

Fig 6 Illustration of the FJWG Facebook-community user analysis based on number of public posts published by 27 FJWG Facebook-followers. The bigger the font, the higher the number of posts published.

Following the Twitter mention-network analysis (Figure 7), we found that the 89 identified Twitter users shared a total of 170 tweets, generating 27 replies, 118 retweets, and 49 likes. The main printed local newspaper The Gazette (featuring two accounts, @ thegazette_news and @ thebtgazette) posted the most tweets of all users (11 and 9 tweets respectively), providing regular information and updates on the different phases of the restoration process. The main governmental actors, Hertfordshire County Council (@DailyHERTS) and DBC (@DacorumBC), shared 9 tweets each, focusing on the restoration and associated participation process, as well as on investment opportunities. These tweets promoted both Councils' political and urban development views on the restoration process for both Councils-to possibly gain public consensus and strengthen synergies with developers. Additional 9 tweets were posted by a non-official Geoffrey Jellicoe account (@G_S_Jellicoe) managed by Lynda Harris, landscape architect and Jellicoe's great-niece, who shared images and information on the reopening of the 
Gardens. Two other individual-user accounts (@ MarionGourd51 and @slv19photos) posted 7 and 5 tweets respectively, sharing images of the newly renovated Gardens. The remaining 111 tweets were posted by 82 individual-user accounts, including the designers involved in the restoration process promoting their professional work (@HTAdesignLLP and DominicColeDCLA). A real-estate investor account shared posts on the Gardens restoration process promoting Hemel Hempstead as a prime choice for business and attracting investors (@investHemel). Other accounts included amateur photographers sharing images of the Gardens’ flora and fauna (@gmstringer and @ andyhartleyuk), as well as accounts associated with automatic tweets generated by applications linking a location with its user (foursquare.com).

\section{[Figure 7]}

Fig 7 Illustration of the mention-network analysis of Twitter users, based on number of published tweets published by Twitter users-including "Hemel Hempstead Water Gardens" as words, hashtags, or location. The bigger the font, the higher the number of posts published by the Twitter user. Colours identify different actor types. Red: governmental; cyan: no-profit non-governmental; blue: profit non-governmental; green: individual.

\section{Discussion}

\subsection{Analysis of the SES framework second-tier variables}

The analysis-selected of all-Resource System second-tier variables we considered (Figure 4) allowed to revealedallowed analysing how the impact of distinctive characteristics of the Gardens water system ean positively impacton the local 
community engagement and self-organizing process. Starting from the size of our Resource System (RS3), we observed that the scale of the Gade channel remains moderate and partially self-contained $(615 \mathrm{~m}$ long), considering the overall size of the town (2350 hectares). The Gardens size (3.5 hectares) can be considered as of a moderated, intermediate scale compared to the smaller pocket parks and playgrounds in the Hemel Hempstead town centre, and the bigger woods and open fields located further North (where the channel crosses the suburban agricultural lands) and South (alongside the main branch of the river). Based on our field observations and in line with Ostrom (2009), we concluded that such a size, together with the channel's central location in the town (parallel to the main commercial road) (Figure 2a and 2b), can facilitate the internal cohesion of the local community (activities that are sustained within and by the community due to the presence of the Gardens, e.g. resting, social meetings, playing, observing the wildlife) and, c. I, which,. Consequently, iI in turn, this thistcan favour the development of the self-organized commoning actions (Ostrom 2009)vities..For example, the Gardens are accessible for resting, as a social meeting place, for play, for appreciating and observing the wildlife and ecology, and for community activities. As demonstrated through previous research on commons (Chhatre and Agrawal 2009), a moderate-sized system can be more conducive to self-organization than small-scale or big-scale resource systems._-These are more-less unlikely to generate self-organization, due to their inability to generate substantial flows (small systems) or due to higher maintenance costs (big systems).

The maintaining of the biological "productivity of the system" (RS5) was demonstrated to be a strong focus of the Gardens commoning actions, and the restoration works more particularly, as a means to maintain anthe ecologically and socially_health and 
functionality of the $y$ water system. During the interviews, the restoration landscape architects affirmed having considered collaborations with the Environmental Agency and local biology and ecology experts as paramount in their work. By contrast, "economic productivity" didn't emerge as a focus of the commoning actions in our fieldwork, differently from other water_-common case studies (Nagendra and Ostrom 2014) and as in-Ostrom's original definition of the RS5 variable. No evidence of actors' intentions to gear the commoning activities to any productive or consumerist use (e.g. commercial fishing) was found in our data collection. Additionally, the eurrent restrictions resulting from the English Heritage's Grade II registration and the predominant recreational function which lies at the core of the management regime in place also-make it difficult to foresee any Moreover, commercial exploitation of the Gade channel is unlikely in the near future, due to the nature of the Gardens, planning restrietions, and consequent stability of the management regime in place. Preservation of the system biological productivity involves "Monitoring activities" (I9, third-tier variable of "Self-organizing activities") through periodic observation of the Gardens' flora and fauna. This was one of the main focuses of the community-engagement activities, as demonstrated by the results of the topic modelling. Species identification and biodiversity counts promoted by FJWG were among the most popular topics on which the FJWG community shared posts on Facebook (Figure 5). Moreover, the gardens volunteers' monitoring system appeared to complement the measurements of water flows and river levels carried out at a UK Environment Agency's hydrometric station located a few miles upstream from the Gardens. As argued in other urban common studies (Langemeyer et al. 2018; Nagendra and Ostrom 2014), cooperation between non-governmental associations and governmental institutions can play a 
critical role in monitoring the ecological performance of a SES and ensuring that ecological values are maintained or improved over time. In the case of the Gardens, the development of collaborative monitoring activities across governmental and nongovernmental actors could be envisioned in the future as a means to strengthen the local commoning actions while favouring the achievement of the social and ecological sustainability objectives pursued by all actor groups.

Moving to the Resource Units second-tier variables, the interviews with the landscape architects in the restoration team and the analysis of the posts on social media showed the strong attention paid by all actor groups (governmental and non-governmental, profit and non-profit) to the presence and values of the local species, as well as to the infrastructural elements designed to integrate the water system into the Gardens and to allow its recreational use (Figure 5). The flora and the infrastructural elements represent both "stationary" units, following analysis of the "mobility" second-tier variable (RU1). In Ostrom (2009), stationary units are associated with a higher likelihood of actors to self-organize and engage in commoning activities, since they require lower monitoring and managing costs than "mobile" resources. Among the mobile resource units, a stronger interest in units recurrently observed in the Gardens was shown by the repetition of the same names of birds, and-fish, and crustaceans species-in the posts (e.g. tits, kingfishers, ducks, geeeøse, chubs, crayfishs). As for the "Governance Systems", the English Heritage's Registration proved a key determinant of the Gardens' self-organized management regime ("Monitoring and Sanctioning rules" GS8). The Registration has substantial impact on the commoning actions due to the associated conservation policy and regulation to which the Gardens are subject (ef.see "Case Study" section). Further, our fieldwork showed that the 
Gardens' actors have no full autonomy and rights to make and enforce their own rules collectively. Hence implementation of "collective-choice rules" (GS6) cannot be contemplated under the governance system currently in place. This makes a substantial difference with other urban commons in which greater local autonomy to establish resource management rules was observed to act as a catalyst for the commoning actions (Ostrom 2009; Chhatre and Agrawal 2009).

In the analysis of the "Actors" subsystem, the results of the analysis of Facebook contents and users (Figure 5 and 6), showed the key role played by FJWG as the main catalyser of the commoning actions and facilitator of the self-organizing process (“Leadership/entrepreneurship" variable A5). FJWG shared 132 posts on their Facebook page (including 1167 images) and additional 54 posts were shared on the same page by their online community (see Results). These posts reflect the role the group played in strengthening the commoning actions especially throughout three key moments in the Gardens recent history: before the construction works (e.g. posts about the launching of the-FJWG inviting people to join their group), during the restoration works (e.g. posts about the public consultation on the play area and construction site visits), and following the reopening (e.g. posts about guided walks and the launching of new activities in the Community Garden). The intensity of the exchanges on social media testifies FJWG's leadership position at these key moments as the result of both physical and virtual interaction with the local community. Moreover, their FJWG's special such a roleposition role proved to bewas facilitated enhanced by their their knowledge of the water system ecological and social values ("Knowledge of SES/mental models" variable A7), which, which they shared during the several recreational and educational programmes organised inside and outside the Gardens 
(ef.see topic words in Figure 5) and . Their knowledge proved to-supported their recognition as leaders in the commoning actions actions by the broader Gardens community (Figure 6). The different types of A clear ambition to share knowledge of the Gardens' social and ecological values was also shown by other private and public actors involved in the commoning also showed a clear ambition to share knowledge of the Gardens' social and ecological values, as manifested in the majority of posts published by the FJWG Facebook followers. Interactions among actors provided the opportunity of gaining new Such posts concentrated mainly knowledge ofon the sharing of information on natural and infrastructural features of the Gardens water systems (local flora and fauna, facilities and structures, restoration works) and the learning of new skills (e.g. gardening, wood crafting workshops). According to Ostrom (2009), knowledge-gaining by actors can significantly enhance the social, ecological, and economic viability of the managed resource. Hence, both community leadership (A5) and knowledge-sharing (A7) proved an effective means to leverage community engagement and consolidate self-organization processes in the Gardens.

Finally, the observed intense online activity and the sharing of Gardens-related posts on a regular basis by the FJWG profile and the other analysed Facebook and Twitter user profiles (ef.see "Results" section) demonstrated a strong general interest in the Resource System by the Actors ("Importance of the Resource", variable A8). However, qualitative indicators to monitor the actors' motivation (including etheractor groups other than FJWG) and the importance they attach to the Gardens' water system could not be identified during our data collection ${ }^{4}$. As observed in similar urban common

\footnotetext{
4-In Ostrom (2008), the A8 variable (named "U8" after Users, see note 1) incorporates consideration of both "how important" a Resource System is for those involved in its governance and the level of dependence of actors from the system. Previous studies of urban water commons incorporating the $A 8$ variable focused, for example, on the actors' dependence on water resources for agriculture, animal
} 
studies (Shah and Garg 2017, Follmann and Viehoff 2015), common interest in the same resource system by different stakeholder groups can positively impact the willingness of the actors to engage in commoning practices. The interviewed HTA landscape architects pointed repeatedly to the strong motivation shown by the actors and their attachment to the Gardens, which contributed to minimizing the organizational efforts required for communication campaigns and networking (ef.see Interactions' third-tier variable "Networking activities" I8). The interviewees reported that the online community proved proactive in sharing information and getting engaged on a daily basis in the restoration process and in the activities connected to the reopening of the Gardens. Overall, the virtual networking among actors appeared to strengthen the collective actions and helped capitalize on complementary expertise and knowledge of the Gardens, while enhancing FJWG's leadership position.

\subsection{Limitations of social-media data analysis}

Analysis of social-media contents and user profiles provided valuable complementary data to archived evidence, field observations and semi-structured interviews (see,_as shown in the "Results")-section. Moreover, it allowed revealing the significant role played by the online networking activities in the Gardens commoning actions. However, methodologies for social-media data mining carries limitations, as stressed in the growing literature on the subject. These include, for example, the limited representation or exclusion of some actor groups, such as elderly, who are potentially less "visible" on social media than other groups (Trentham et al. 2015) but can be

\footnotetext{
farming and groundwater recharge (e.g. Nagendra and Ostrom 2014). However, in our case, the actors were clearly not in a situation of material or physical dependence from the Reseurce System. Measuring the importance of the resource system for actors requires a different methodology than assessing and monitoring levels of dependence from it.
} 
actively engaged in commoning actions. However, for case studies in Great Britain, it should be noted that a $17 \%$ increase in the number of social-media users aged 55-64 (from $30 \%$ to $47 \%$ ) and a $9 \%$ increase for users aged $65+$ (from $18 \%$ to $27 \%$ ) was observed between 2011 and 2018 (in parallel to an overall 20\% increase across all group ages, from $45 \%$ to $65 \%$ ), and this growing trend is predicted to continue in the future (ONS 2018 and 2011).

Another limitation $\theta$ fin the analysis of social-media data analysis-consists of their relatively higher level of noise compared to other data mining techniques (Cobb 2015). In order to limit the noise level, more selective data-cleaning was required in our case study. Moreover, a higher level of subjectivity and more "human judgment" (Kim et al. 2018) was needed to interpret contents of posts or tweets and classify them in a comprehensive topic-modelling framework (e.g. coupling words, deducing broader topics from individual words or syntagma). In sum, data mining from social media needs more reliable analytical methods and more rigorous validation process (Kim et al. 2018). However, as in our case, social-media datasets can be used to triangulate data sourced through more traditional methods and can help test research hypotheses through the use of a wider spectrum of input data.

\section{Conclusions and further research}

Our initial working hypothesis was that water systems may be-incorporated into urban designsspaces andmay be applied to the prove valuable forfosteringing of commoning practices in a SES. For the purpose of assessing this hypothesis we analysed what might be the leverages for self-organization in urban water commons, representing one typology for SESs. In line with our initial working hypothesis, the results of our study 
ef The application of the Ostrom's SES framework in the study of Jellicoe's Hemel

Hempstead Water Gardens demonstrate that the presence of water systems can leverage self organization and enhance foster stakeholder engagement in urban commons. The application of the Ostrom's SES framework allowed-supported the evaluation ofng how the-distinctive natural and infrastructural features of the Gardens water system which may play a role in fosteringstrengthening -community engagement and the local the ongoing self-organizing process-could be strengthened community engagement through recreational and networking activities in the Gardens water system. could foster catalyse the ongoing self-organizing process and strengthen the bottom-up governance systems in place. Our application isstudy was supported-informed by evidence gathered through across a wide-broad spectrum of sources and analytical techniques. These include, from-more traditional qualitative data collection and interpretation (analysis of archived drawings and reports on Jellicoe's original project, field work and in-situ observations, as well as semi-structured interviews)-to data mining from social media._topic modelling of Facebook posts, review of Facebook user profiles, and Twitter mention-network analysis). The online networking activities among different stakeholder groups (local authorities, landseape architects involved in the recent restoration, volunteer groups and individuals, as well as local press and investors)-appeared to play a key role in strengthening the collective actions and in consolidating the urban commoning practices in the Gardens. Moreover, they allowed the consolidation ofng a common reservoir of expertise and knowledge of the Gardens, while underpinning and strengthening alimenting the actors' common interest in the peculiar natural and infrastructural components of the Gardens:- (the flora and fauna inhabiting the channel, the construction works and their progress, the renovated bridges, 
viewing platforms, and other recreational facilities following the reopening). Finally, $\underline{a}$ As reflected in the continued online communication on social media, the leadership ubiquitous presence and entrepreneurial capacityposition held byof the local charity (FJWG) atacross key moments of the Gardens' recent history (e.g. before and throughout the restoration process as well as following the reopening) ef the loeat eharity (FJWG) proved an essential driver forwas a critical component in strengthening the self-organizing process- through continued online communication as well as physical engagement in knowledge-sharing and all age recreational activities on the water (e.g. self organized observation of local species and biodiversity monitoring, reading groups, hands on educational programmes for children and young adults). The regular presence of the local volunteer group both virtually and physically "on the ground", as well as the recognition of their knowledge and expertise on the Gardens,and allowed catalysing the knowledge-sharing and all-age-recreational and knowledgesharing activities on the water.(e.g. self-organized observation of local species and biodiversity monitoring, reading groups, hands on educational programmes for children and young adults). proved essential to catalyse and streamline the collective action. Our analysis carries the limitations that are inherent to all-single case studies. A comparative study with other urban water commons with similar or contrasting characteristics is essential to generalise our findings and further test our hypothesis. $\underline{\text { However, any comparative effort should acknowledge the peculiarity of the Gardens }}$ case resulting from the international reputation of his landscape designer (Geoffrey Jellicoe) and the impact of the regulation restrictions introduce with the English Heritage Registration. It can be argued that this condition makes the Gardens more similar to an architectural "landmark" than to a conventional urban park (e.g. the 
restoration works received international coverage well beyond the Hemel Hempstead community and local press). The Gardens' fame and consequent visibility of the local community on athe national orand even international scene might have influenced the behaviour of some actor groups involved in the commoning actions. A cross-case study focusing on a more ordinary urban water common could, for example, support the validation or dismissal of this hypothesis. Moreover, a longitudinal study comparingsen the commoning actions and behaviours of the actor groups before and after the Gardens restoration could help ascertain to what extent this intervention had contributeding to at revamping of the engagement of all parties (despite the "conservative" ambition reported by HTA in the interviews). Finally, returning to the emerging link between commoning and sustainability goals as-observed in other urban commons cases (see Introduction), our analysis provided little evidence of the impact of the local actions on the actual sustainability conditions and resilience of the Gardens SES. Last but not least, more evidence on the socioeconomic profiles of the actors involved (e.g.; income levels and socio-demographics) $)$ is critical to properly investigate the social inclusivity of the groups and actions shaping the Gardens commons. As in all SES studies, the variety of the social groups represented in commoning actions need further attention. This is essential to understand whether the adopted governance systems areis far-reaching enough for a resilient SES to be maintained and prosper over time.

In the long term, community building and self organization efforts among actor groups in the Gardens could may be oriented toward the achievement of broader and more ambitious sustainability goals (as observed in the abovementioned urban commons eases). Beyond the current prevailing recreational purposes, commoning actions could be further leveraged jointly by the governmental and non-governmental sectors in order 
to foster the development of more functional social-ecological resilience models for the whole Gardens system.

\section{Acknowledgments}

The authors are grateful to Dacorum Borough Council - Parks and Green Spaces, and to the HTA Design LLP members of staff (London Office) who agreed to be interviewed took part in the interviews-and shared internal reports and planning documents on the restoration of the Hemel Hempstead Water Gardens, as well as to the archivists at the Museum of English Rural Life (Landscape Institute Collection) and at the Hertfordshire Archives and Local Studies; for their support during our research (Jellicoe's original drawings and reports on the Water Gardens project).

\section{Conflict of Interest}

The authors declare that they have no conflict of interest.

\section{References}

Acosta C, Ortega M, Bunsen T, Koirala BP, Ghorbani A (2018) Facilitating Energy Transition through Energy Commons: An Application of Socio-Ecological Systems Framework for Integrated Community Energy Systems. Sustainability 10(2): 366 http://doi.org/10.3390/su10020366

Blei, D.M. (2012) Probabilistic topic models. Communications of the ACM 55(4): 7784. https://doi.org/10.1145/3186262 
Chhatre A, Agrawal A (2009) Trade-offs and synergies between carbon storage and livelihood benefits from forest commons. Proceedings of the National Academy of Sciences 106(42): 17667-17670. https://doi.org/10.1073/pnas.0905308106

Colding J, Barthel J (2013) The potential of 'Urban Green Commons' in the resilience building of cities. Ecological Economics 86: 156-166.

https://doi.org/10.1016/j.ecolecon.2012.10.016

Colding J, Barthel S, Bendt P, Snep R, van der Knaap W, Ernstson H (2013) Urban green commons: Insights on urban common property systems. Global Environmental Change 23: 1039-1051. http://dx.doi.org/10.1016/j.gloenvcha.2013.05.006

Cobb WNW (2015) Trending now: Using big data to examine public opinion of space policy. Space Policy 32: 11-16. https://doi.org/10.1016/j.spacepol.2015.02.008

Cracknell D, Pahl S, White M, Depledge M (2018) Reviewing the role of aquaria as restorative settings: how subaquatic diversity in public aquaria can influence preferences, and human health and well-being. Human Dimensions of Wildlife, 23:5: 446-460. https://doi.org/10.1080/10871209.2018.1449039

Egerer M, Fairbairn M (2018) Gated gardens: Effects of urbanization on community formation and commons management in community gardens. Geoforum 96: 61-69. https://doi.org/10.1016/j.geoforum.2018.07.014

Elmqvist T, Folke C, Nyström M, Peterson G, Bengtsson J, Walker B, Norberg J (2003) Response diversity, ecosystem change, and resilience. Frontiers in Ecology and the Environment 1: 488-494. https://doi.org/10.1890/15409295(2003)001[0488:RDECAR]2.0.CO;2 
Follmann A, Viehoff V (2015) A green garden on red clay: creating a new urban common as a form of political gardening in Cologne, Germany. Local Environment 20(10): 1148-1174. http://dx.doi.org/10.1080/13549839.2014.894966

Frey UJ (2017) A synthesis of key factors for sustainability in social-ecological systems. Sustainability Science 12(4): 507-519. https://doi.org/10.1007/s11625-016$\underline{0395-\mathrm{Z}}$

Jellicoe GA (1947). The Report accompanying a plan for Hemel Hempstead New Town. Prepared for the Hemel Hempstead Development Corporation, 3rd June 1947. Jellicoe, Ballantyne \& Coleridge Chartered Architects (1960). Specification of works to be executed, plants and materials to be provided, for the planting of Water Gardens at Hemel Hempstead, under the supervision of, and to the satisfaction of, Messrs. Jellicoe, Balantyne and Coleridge. April 1960.

Kim HJ, Chae BK, Park SB (2018) Exploring public space through social media: an exploratory case study on the High Line New York City. Urban Design International 23(2): 69-85. https://doi.org/10.1057/s41289-017-0050-Z

Langemeyer J, Camps-Calvet M, Calvet-Mir L, Barthel S, Gómez-Baggethun E (2018) Stewardship of urban ecosystem services: understanding the value(s) of urban gardens in Barcelona. Landscape and Urban Planning 170: 79-89. http://dx.doi.org/10.1016/j.landurbplan.2017.09.013

Marshall G (2008) Nesting, subsidiarity, and community-based environmental governance beyond the local. International Journal of the Commons 2(1): 75-97. http://doi.org/10.18352/ijc.50

McGinnis MD, Ostrom E (2014) Social-ecological system framework: initial changes 
and continuing challenges. Ecology and Society 19(2): 30.

http://dx.doi.org/10.5751/ES-06387-190230

Mundoli S, Manjunath B, Nagendra H (2015) Effects of urbanisation on the use of lakes as commons in the peri-urban interface of Bengaluru, India. International Journal of Urban Sustainable Development 7 (1): 89-108.

https://doi.org/10.1080/19463138.2014.982124

Murphy A, Enqvist JP, Tengö M (2019) Place-making to transform urban socialecological systems: insights from the stewardship of urban lakes in Bangalore, India. Sustainability Science 14(3): 607-623. https://doi.org/10.1007/s11625-019-00664-1 Nagendra H, Ostrom, E (2014) Applying the social-ecological system framework to the diagnosis of urban lake commons in Bangalore, India. Ecology and Society 19(2): 67. http://dx.doi.org/10.5751/ES-06582-190267

ONS (Office for National Statistics, UK) (2018), Internet access - households and individuals, Great Britain. Published 8 August 2018. Available at:

https://www.ons.gov.uk/peoplepopulationandcommunity/householdcharacteristics/hom einternetandsocialmediausage/datasets/internetaccesshouseholdsandindividualsreferenc etables Accessed 4 July 2019

ONS (Office for National Statistics, UK) (2011), Internet access - households and individuals, Great Britain. Available at:

https://www.ons.gov.uk/peoplepopulationandcommunity/householdcharacteristics/hom $\underline{\text { einternetandsocialmediausage/datasets/internetaccesshouseholdsandindividualsreferenc }}$ etables Accessed 4 July 2019 
Ostrom E (1990) Governing the Commons. The Evolution of Institutions for Collective Action. Cambridge University Press, Cambridge.

Ostrom E (2007) A diagnostic approach for going beyond panaceas. Proceedings of the National Academy of Sciences 104 (39):15181-15187.

http://dx.doi.org/10.1073/pnas.0702288104

Ostrom E (2008) The challenge of common pool resources. Environment 50: 8-21. https://doi.org/10.3200/ENVT.50.4.8-21

Ostrom E (2009) A general framework for analyzing sustainability of social-ecological systems. Science 325:419-422. http://dx.doi.org/10.1126/science.1172133

Ostrom E, Ahn TK (2003) Introduction to Foundations of social capital. Edward Elgar, Cheltenham, UK, pp xi-xxxix

Partelow S (2016) Coevolving Ostrom's social-ecological systems (SES) framework and sustainability science: four key co-benefits. Sustainability Science 11(3): 399-410. https://doi.org/10.1007/s11625-015-0351-3

Perrotti D, Iuorio O (2018) Green Infrastructure in the Space of Flows: An Urban Metabolism Approach to Bridge Environmental Performance and User's Wellbeing. In Lemes de Oliveira, F. and Mell, I. (eds.), Planning Cities with Nature: Theories, strategies and methods. Dordrecht: Springer, pp 265-277. https://doi.org/10.1007/978-3$\underline{030-01866-5 \quad 18}$

Petrescu D, Petcou C, Baibarac C (2017) Co-producing commons-based resilience: lessons from R-Urban. Building Research \& Infromation 44(7): 717-736. http://dx.doi.org/10.1080/09613218.2016.1214891 
Radywyl N, Biggs C (2013) Reclaiming the commons for urban transformation. Journal of Cleaner Production 50: 159-170. http://dx.doi.org/10.1016/j.jclepro.2012.12.020

Rodgers CP, Straughton E, Winchester AJL, Pieraccini M (2011) Common Land as a Contested Resource. In id. (eds.) Contested Common Land. Environmental Governance Past and Present. London: Routledge, p. 1-16.

Shah A, Garg A (2017) Urban commons service generation, delivery, and management: A conceptual framework. Ecological Economics 135: 280-287.

http://dx.doi.org/10.1016/j.ecolecon.2016.12.017

Spens M (1994) The Complete Landscape Designs and Gardens of Geoffrey Jellicoe. Thames \& Hudson, London.

Trentham B, Sokoloff S, Tsang A, Neysmith S (2015) Social media and senior citizen advocacy: an inclusive tool to resist ageism? Politics, Groups, and Identities, 3(3): 558571. https://doi.org/10.1080/21565503.2015.1050411 


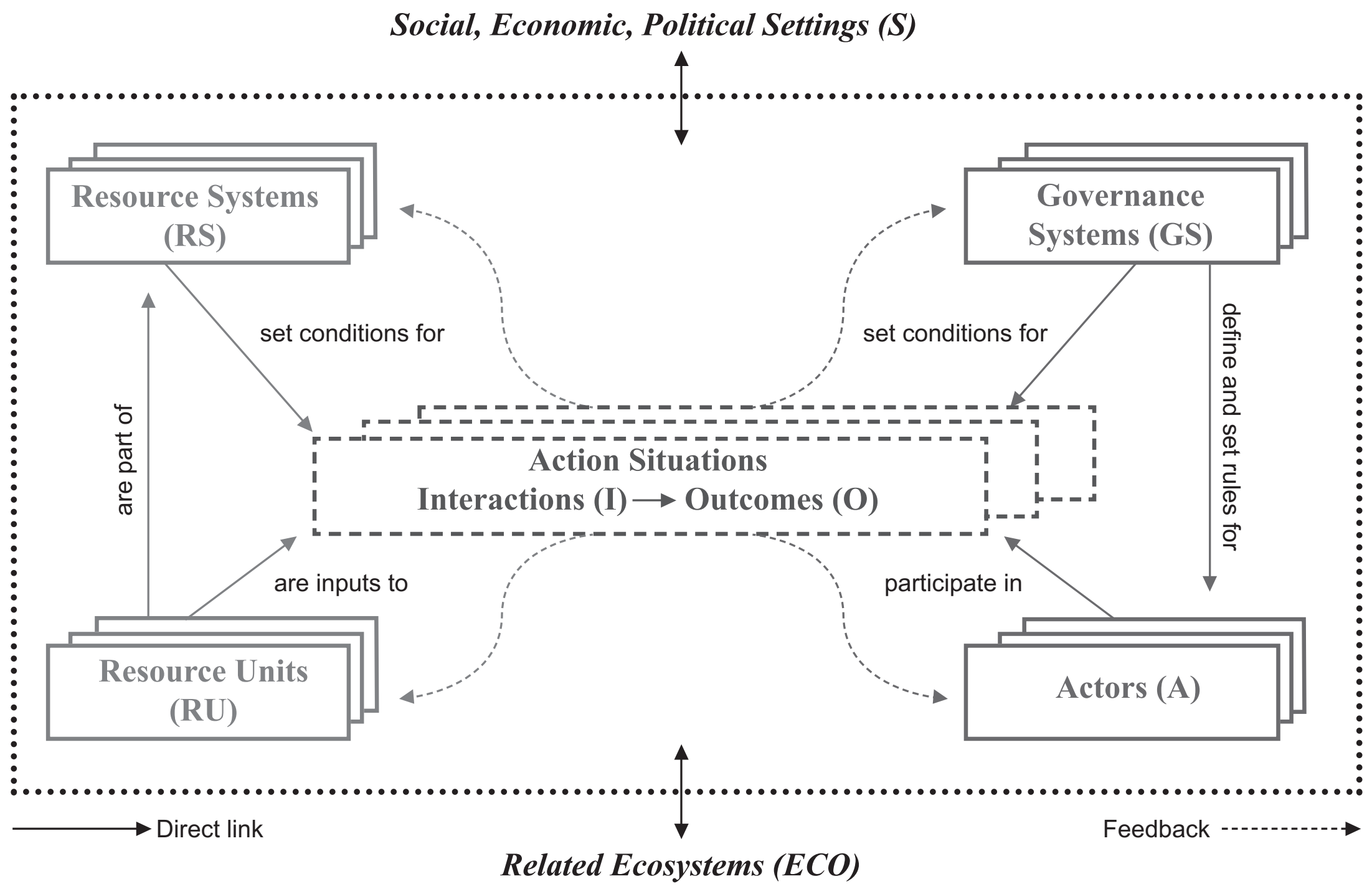

Social, Economic, Political Settings (S) 

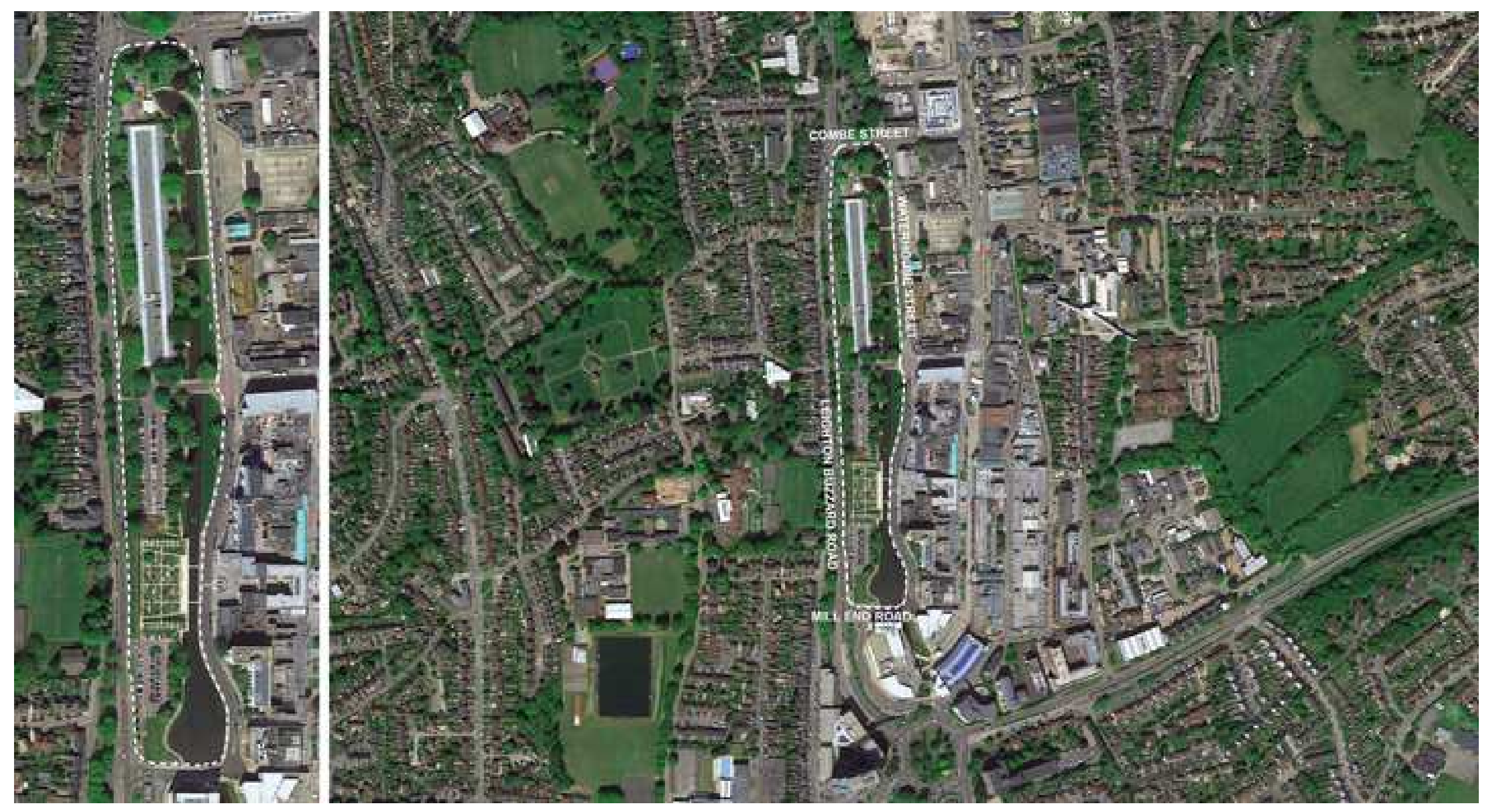


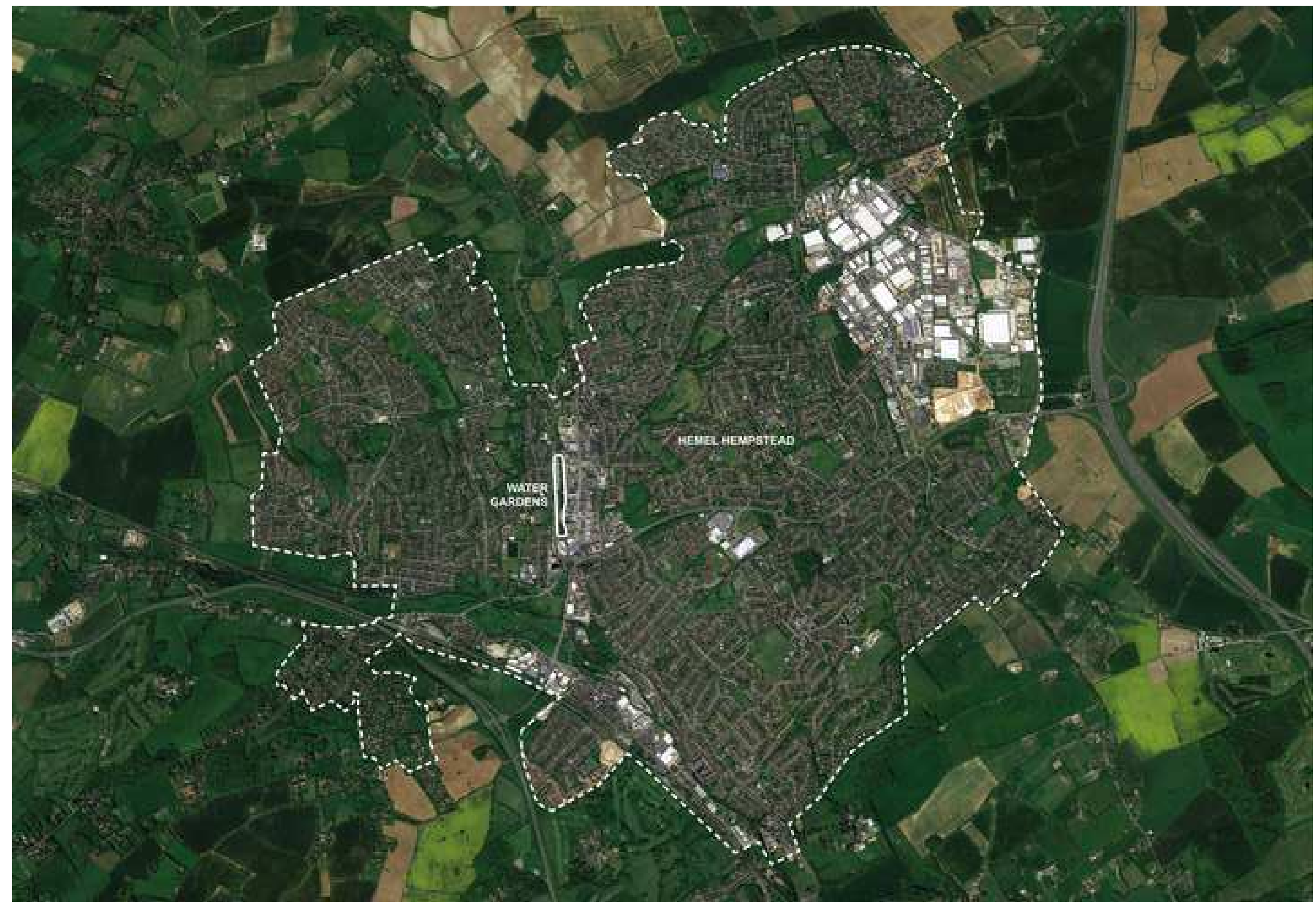




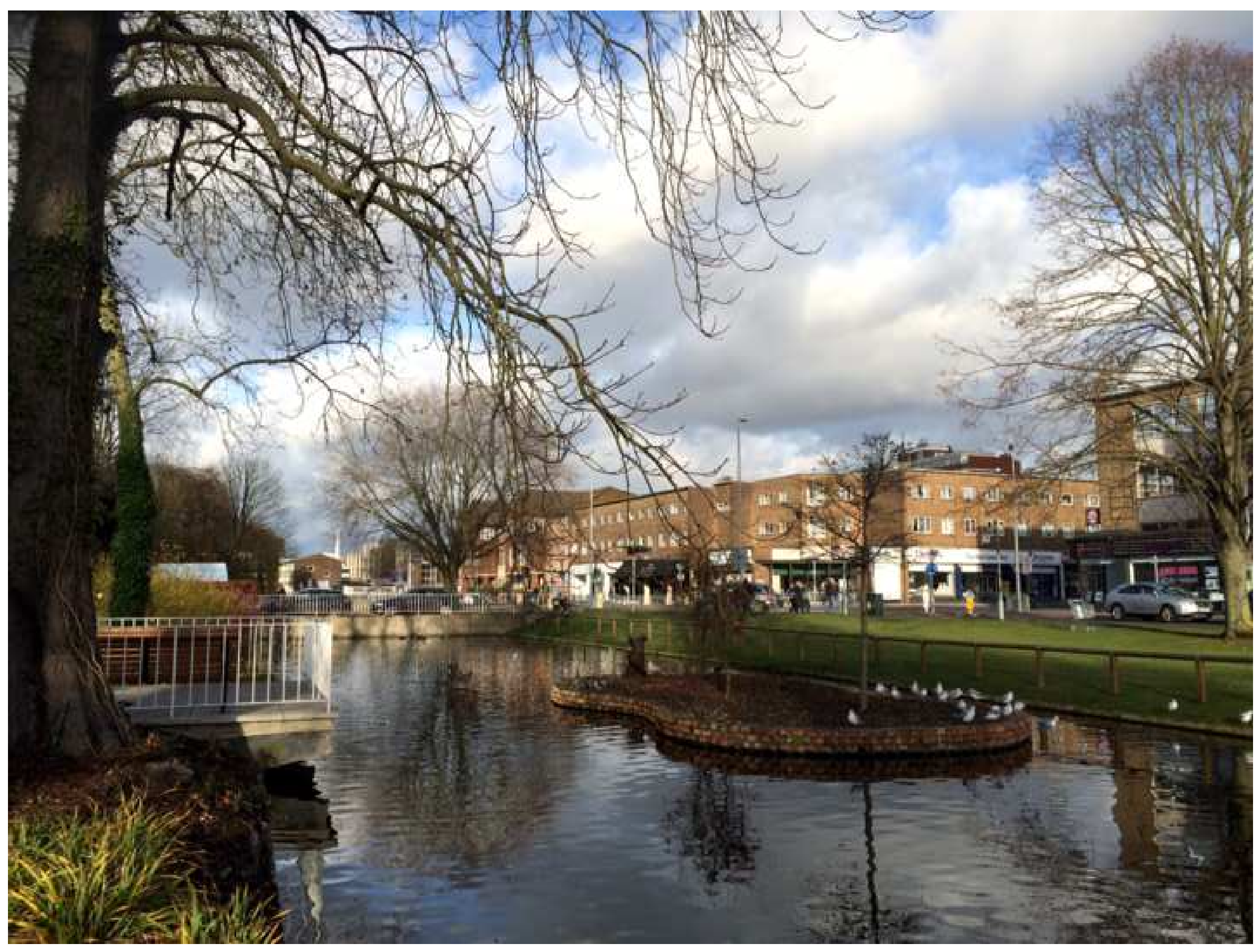




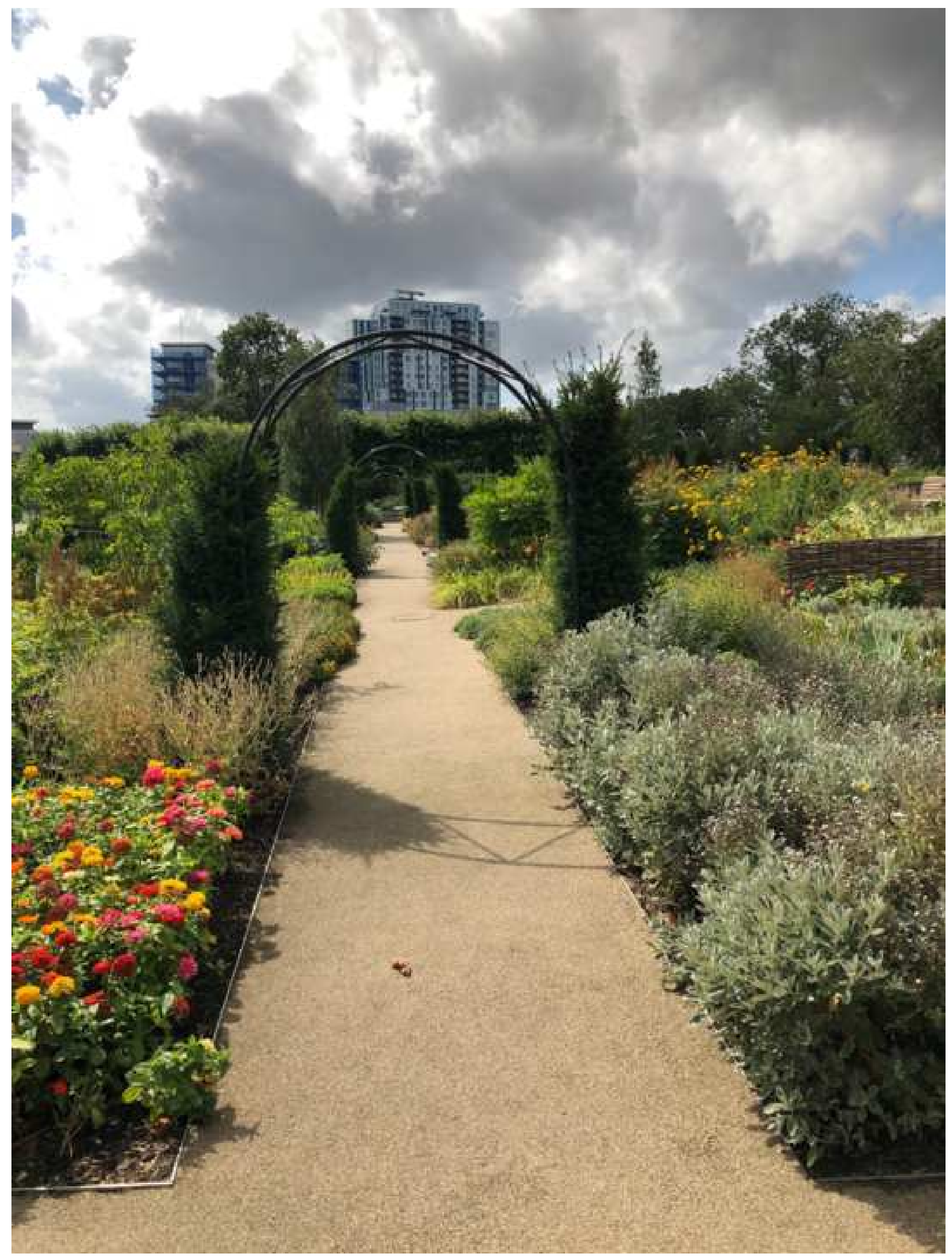


FIRST-TIER

VARIABLES/SUBSYSTEMS
USED

SECOND-TIER VARIABLES IN CASE

STUDY

Action situations: Interactions

Action situations: Int
$(\mathrm{I}) \rightarrow$ Outcomes $(\mathrm{O})$

$$
\text { a. }
$$

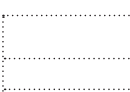$$
\text { I1 - Harvesting }
$$

I2 - Information sharing

I3 - Deliberation processes

I4 - Conflicts

I5 - Investment activities

I6 - Lobbying activities

I7 - Self-organizing activitie

I8 - Networking activities

$$
\text { ities }
$$

I9-Monitoring activities

I10 - Evaluative activities O1-Social performance measures (e.g., efficiency, equity, accountability, sustainability)

O2 - Ecological performance measures (e.g., overharvested, resilience, .….............. Yes biodiversity, sustainability)

O3 - Externalities to other SESs RS1 - Sector (e.g., water, forests, pasture, fish)

RS2 - Clarity of system boundaries

RS3 - Size of resource system*

RS4 - Human-constructed facilities

RS5 - Productivity of system*

RS6 - Equilibrium properties RS7 - Predictability of system dynamics*

RS8 - Storage characteristics

RS9 - Location

.. RU1 - Resource unit mobility*

RU2 - Growth or replacement rate

RU3 - Interaction among resource units

Resource units (RU)

RU4

Number of units

RU6 - Distinctive characteristics

RU7 - Spatial and temporal

distribution

GS1 - Government organizations

GS2 - Nongovernment organizations

GS3 - Network structure

GS4 - Property-rights systems

Governance systems (GS)

GS5 - Operational-choice rules .

GS6 - Collective-choice rules*..

GS7 - Constitutional-choice rules

GS8 - Monitoring and sanctioning

rules

A1 - Number of relevant actors

A2 - Socioeconomic attributes

A3 - History or past experiences

A4 - Location

A5 - Leadership/entrepreneurship*

A6 - Norms (trust-reciprocity)/ social capital*

A7 - Knowledge of SES/mental

models*

A8 - Importance of resource (dependence)*

.. A9 - Technologies available

\section{.... No}

No

No

No

No

... No

No

Yes

Yes

Yes

No

Yes

.

s

No

o

No

No

Yes

No

o

No

es

No

o

No

No

Yes

Yes

o

o

No

o

Yes

No

No

Yes

Yes

Yes

Yes

No
REASON FOR INCLUSION OR EXCLUSION IN CASE STUDY

Not relevant for Research Question (focus on self-organization, I7)

Not relevant for Research Question - see above

Not relevant for Research Question - see above

-Not relevant for Research Question - see above

Not relevant for Research Question - see above

Not relevant for Research Question - see above

- Studied Focal Action Situation - I7-O1/O2 nexus

Integrated as third-tier variable of 17 - online

networking significantly strengthens the

self-organizing process of Gardens actors

Integrated as third-tier variable of 17 -monitoring

of Gardens' flora and fauna is one of the main

activities favouring self-orgnization

Not relevant for case study

Studied Focal Action Situation - I7-01/O2 nexus

Studied Action Situation - I7-O1/O2 nexus

Not relevant for case study

N/A - Not identified by Ostrom (2009) as related to self-organization

N/A - see above

Moderate size of SES is conducive to

self-organization

N/A - see above

Biological Productivity is essential to maintain

an ecologically-healthy water system

N/A - see above

Not relevant for case study - stable

management regime of SES

N/A - see above

N/A - see above

Permanent RUs and recurrently-observed

mobile RUs in SES are conducive to

self-organization

N/A - see above

N/A - see above

N/A - see above

$\mathrm{N} / \mathrm{A}-$ see above

N/A - see above

N/A - see above

Role of Dacorum planning authority in management regime

Non-profit (FJWG) + profit (HTA Design LLP).

Impacts on management regime

N/A - see above

N/A - see above

N/A - see above

Not relevant for case study - Actors have no

full autonomy to $\mathrm{craft} /$ reinforce rules

N/A - see above

Impact of Grade II Registration English

Heritage on planning regime

Large groups of Actors are conducive to

self-organization

N/A - see above

N/A - see above

N/A - see above

Role of FJWG as catalyser of commoning

actions

Sharing of social/cultural norms among Actors is conducive to self-organization

Knowledge-sharing as key commoning action

Motivation/shared interest in SES is conducive to self-organization - could not be monitored

N/A - see above 
trees, plants, roses, flower-beds, flowers, grass, bushes, blooms, apple, mini-orchard, blossoming, conifers, blooming, blossom, pumpkin, tulips, crops, fresh-green-leaves, vegetables, aquatic-species, Japanese-maple cabbage-rose, potencilla, polyanthus, periwinkle, bluebells, sprouting, forsythia, flowering, daffodils, lavender, tomatoes, paeonies, pumpkins, foliage, conkers, crocus, leaves, beans, tree, iris, pears

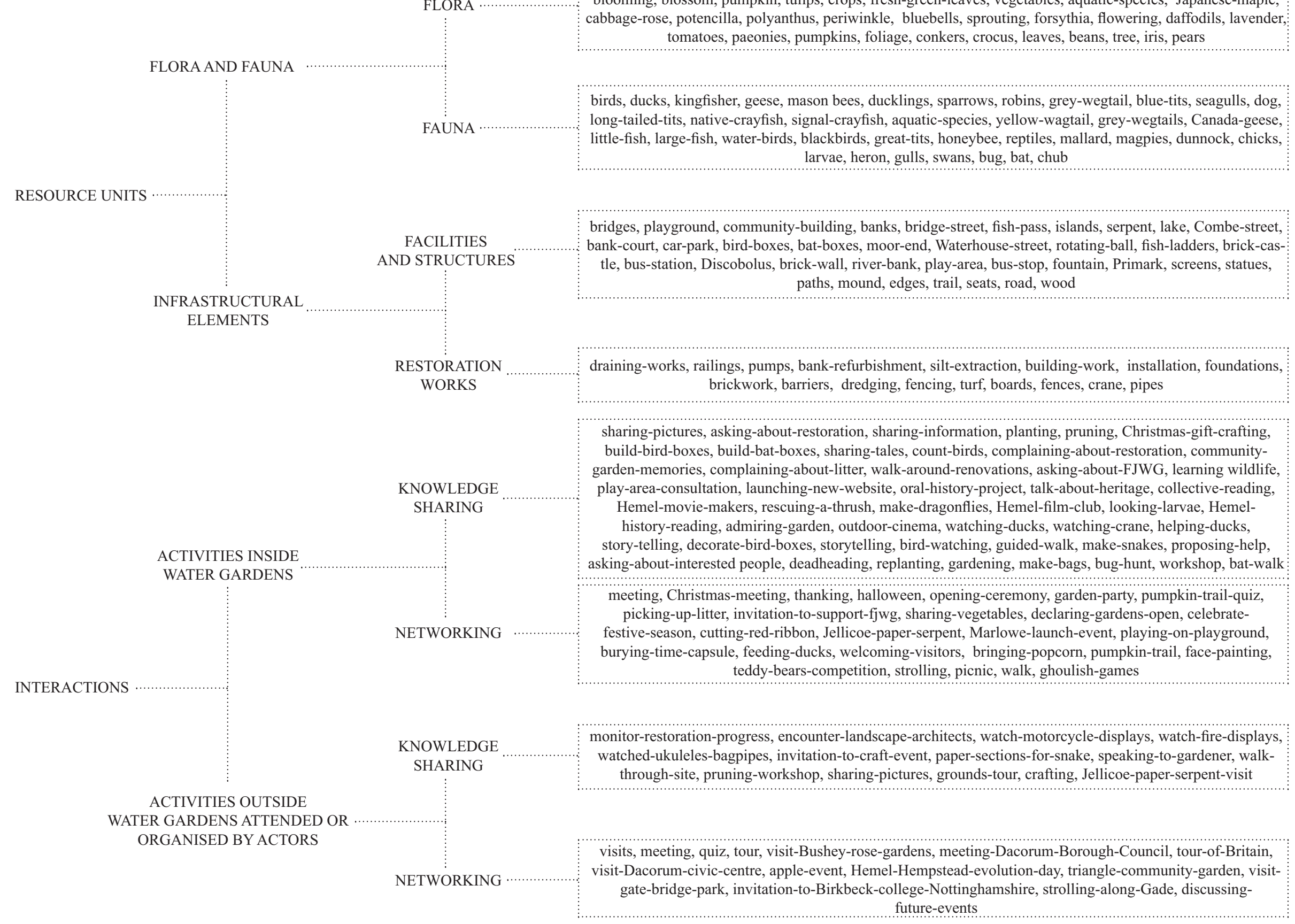

作, long-tailed-tits, native-crayfish, signal-crayfish, aquatic-species, yellow-wagtail, grey-wegtails, Canada-geese,

\section{8}

.

bridges, playground, community-building, banks, bridge-street, fish-pass, islands, serpent, lake, Combe-street,
bank-court, car-park, bird-boxes, bat-boxes, moor-end, Waterhouse-street, rotating-ball, fish-ladders, brick-cas36 WORDS

\section{"}




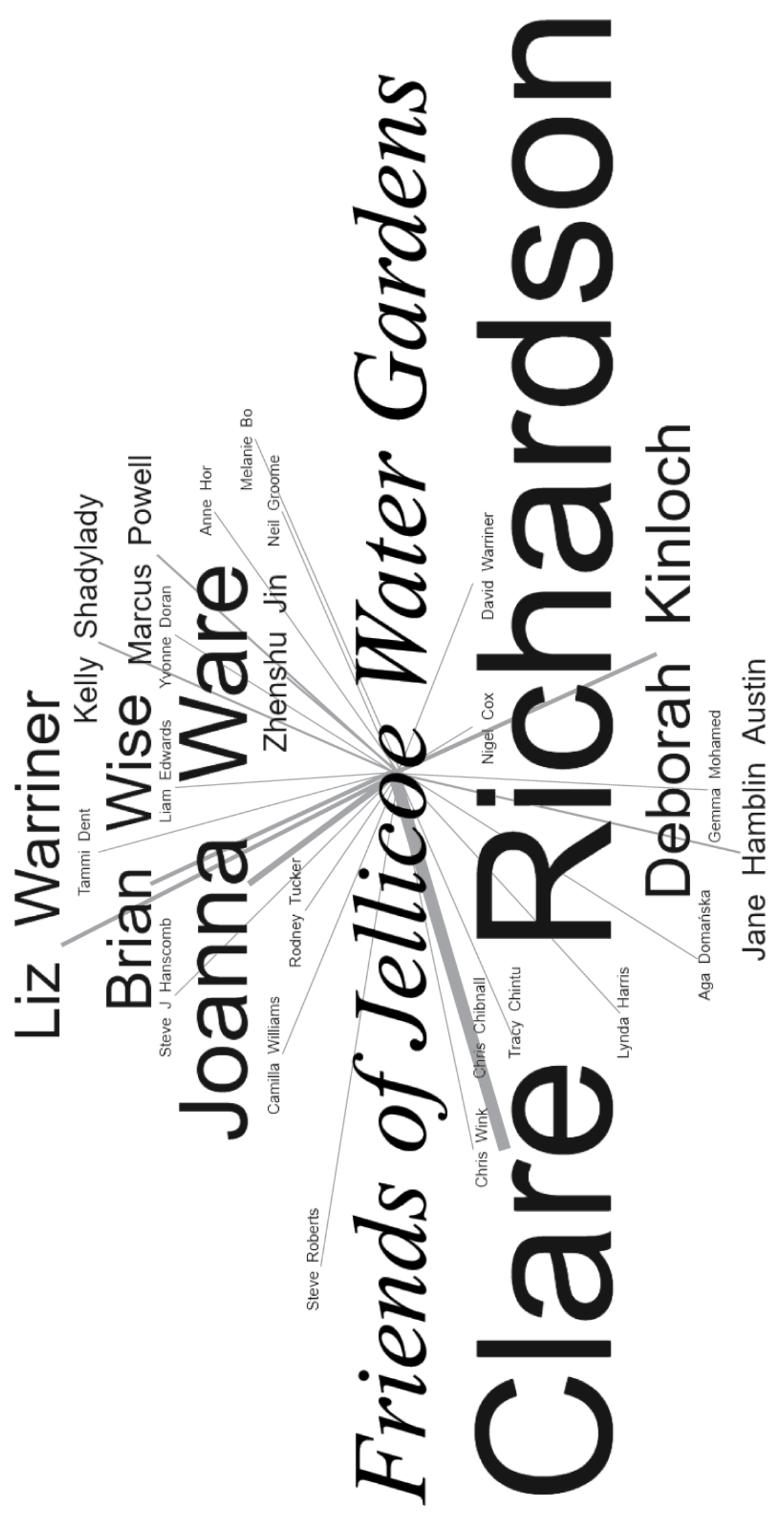

Figure 6 


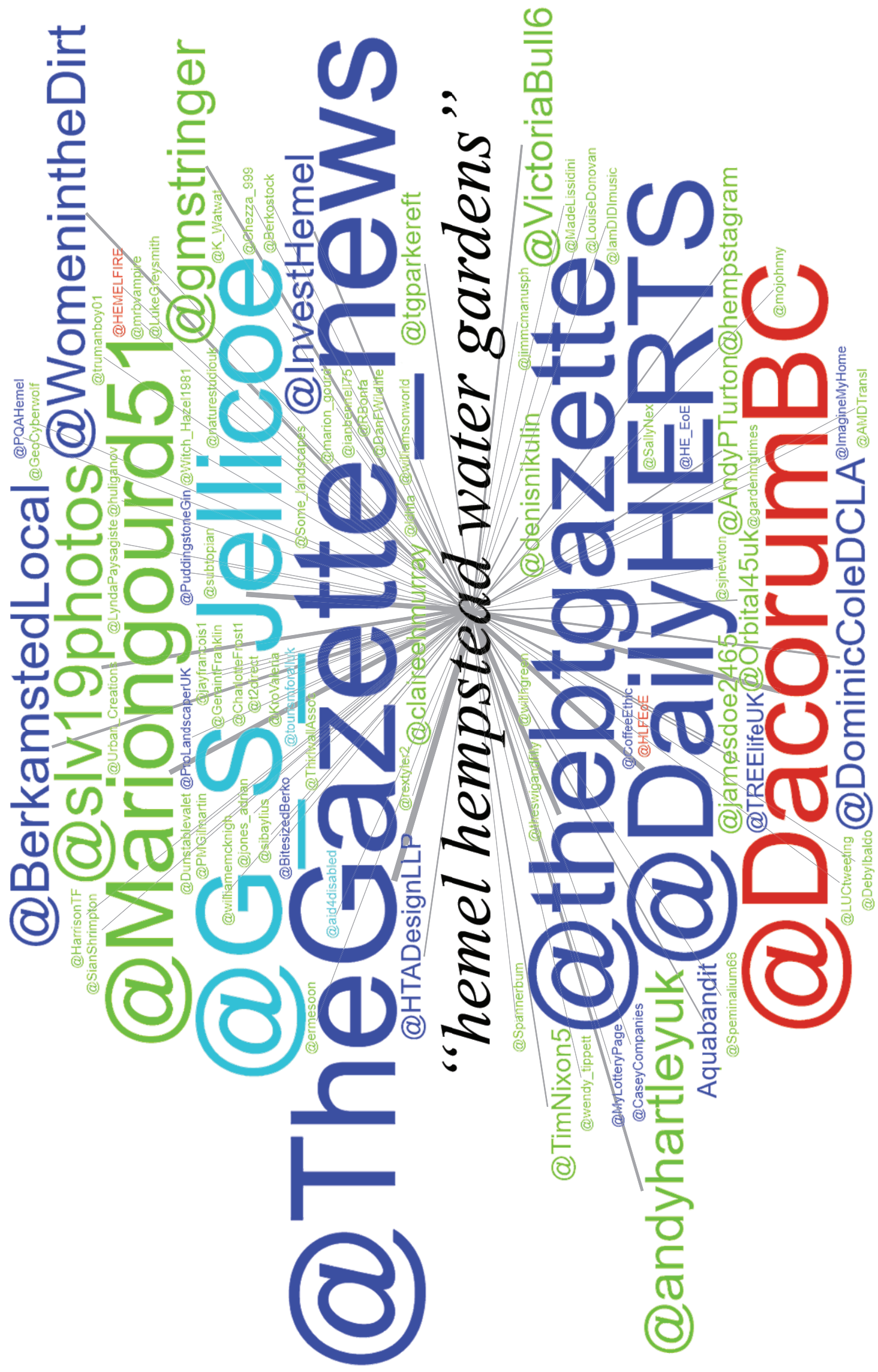

